NBER WORKING PAPER SERIES

\title{
LABOR-FORCE HETEROGENEITY AND ASSET PRICES: THE IMPORTANCE OF SKILLED LABOR
}

\author{
Frederico Belo \\ Xiaoji Lin \\ Jun Li \\ Xiaofei Zhao
}

Working Paper 21487

http://www.nber.org/papers/w21487

\author{
NATIONAL BUREAU OF ECONOMIC RESEARCH \\ 1050 Massachusetts Avenue \\ Cambridge, MA 02138 \\ August 2015
}

We thank Philip Bond, John Boyd, Gianluca Clementi, Andres Donangelo, Bob Goldstein, Francois Gourio, Alexander Michaelides (BI-CAPR workshop discussant), Vincenzo Quadrini, Miguel Palacios (SFS discussant), Fabrizio Perri, Johan Walden (WFA discussant), Toni Whited, and Chen Xue for helpful comments and suggestions. We also thank seminar participants at the University of Minnesota, the Society of Economic Dynamics (SED) 2014 meetings in Toronto, the Society of Financial Studies (SFS) 2015 Finance Cavalcade in Atlanta, the Western Finance Association (WFA) 2015 meetings in Seattle, the BI-CAPR 2015 workshop on Investment and Production Based Asset Pricing for comments. All errors are our own. The views expressed herein are those of the authors and do not necessarily reflect the views of the National Bureau of Economic Research.

NBER working papers are circulated for discussion and comment purposes. They have not been peerreviewed or been subject to the review by the NBER Board of Directors that accompanies official NBER publications.

(C) 2015 by Frederico Belo, Xiaoji Lin, Jun Li, and Xiaofei Zhao. All rights reserved. Short sections of text, not to exceed two paragraphs, may be quoted without explicit permission provided that full credit, including $(\mathcal{C}$ notice, is given to the source. 
Labor-Force Heterogeneity and Asset Prices: the Importance of Skilled Labor

Frederico Belo, Xiaoji Lin, Jun Li, and Xiaofei Zhao

NBER Working Paper No. 21487

August 2015

JEL No. E13,E22,E23,E24,E44,G12

\begin{abstract}
We introduce labor-force heterogeneity in a neoclassical investment model. In the baseline model, we highlight the fact that labor adjustment costs are higher for high skilled workers than for low skilled workers. The model predicts that the negative hiring-expected return relation should be steeper in industries that rely more on high skilled workers because firm's hiring responds less elastically to changes in the discount rate when labor adjustment costs are higher. In an extended version of the model we show that the previous prediction also holds in the presence of additional sources of labor-force heterogeneity such as higher wage rigidity of high skilled workers. Empirically, we document that the negative hiring-expected return relation is between 1.7 and 3.2 times larger in industries that rely more on high skilled workers, than in industries that rely more on low skilled workers. This result is robust: it holds in U.S data, in international data, across sub-samples, and in both firm-level and portfolio-level analyses. Taken together, our results show that labor-force heterogeneity affects asset prices in financial markets.
\end{abstract}

Frederico Belo

Carlson School of Management

University of Minnesota

321 19th Avenue South

Minneapolis, MN 55455

and NBER

fbelo@umn.edu

Xiaoji Lin

Department of Finance

Ohio State University

2100 Neil Ave

Columbus, OH, 43210

lin.1376@osu.edu
Jun Li

University of Texas at Dallas

800 West Campbell Road

Richardson, TX 75080

Jun.Li3@utdallas.edu

Xiaofei Zhao

University of Texas at Dallas

800 W Campbell Road

Richardson, TX 75080

xiaofei.zhao@utdallas.edu 


\section{Introduction}

Labor is not a homogenous input in firms' production technology. There is a large heterogeneity in the labor force - a high skilled worker (for example, an engineer) is a different input from a low skilled worker (for example, a janitor). While low skilled workers execute routine tasks and are relatively easier to hire and replace, high skilled workers execute complex tasks and are costly to hire and replace. Given their different nature, workers with different levels of skills play different roles in firms' production processes, and thus contribute differently for the properties of firms' cash flows and hence firms' value and risk. In this paper, we examine the impact of labor-force heterogeneity on firms' value and risk in the cross section of publicly traded firms in the U.S., as well as in other international markets.

To establish the theoretical link between labor-force heterogeneity and asset prices in the cross section, we introduce labor-force heterogeneity in the neoclassical investment model proposed by Belo, Lin, and Bazdresch (2014) (henceforth BLB). Firms' managers make hiring and investment decisions to maximize the value of the firm, taking as given a stochastic discount factor to value its endogeneous cash flows. There are labor market frictions: labor hiring and firing is costly for firms, which we capture through an adjustment cost function. There are two sources of aggregate risk: aggregate productivity (TFP) shocks, and aggregate adjustment cost shocks. We then consider two industries that differ in the type of labor force used in the production process: one industry uses high skilled workers (high skill industry), whereas the other industry uses low skilled workers (low skill industry). Through comparative statics, we use the theoretical model to obtain several empirical predictions linking the firm's hiring decisions and asset prices in the two industries, which we then test in the data.

The key difference between high skilled and low skilled workers that we emphasize in the baseline specification of the model is that it is more costly to hire and fire a high skilled worker than a low skilled worker, consistent with the empirical evidence that we discuss in detail in the related literature section below (we examine other dimensions of labor-force heterogeneity in an extended version of the model). This specification is natural because the worker screening, selection, and hiring process is more difficult for jobs that require very specialized skills given that these skills are not easy to identify. In addition, the training of a high skilled worker is more costly because of the higher complexity of the tasks that the worker has to perform. Furthermore, high skilled workers possess firm-specific capital or firm-specific relationship with the firm, which makes it particularly costly for firms to fire skilled workers because this would destroy firm-specific capital. This makes high skilled 
workers appear to have higher firing costs as well.

Consistent with standard neoclassical theory of investment, the model predicts a negative relation between the firm's hiring rate and its expected stock return (risk premium). This result is intuitive. Like any investment decision, labor adjustment costs make the firm's hiring decision to be forward looking: optimal hiring is determined by an intertemporal trade-off between the marginal cost of hiring a worker today, and the marginal benefit given by the expected risk adjusted present discounted value of the cash flows generated by the new worker in the future. All else equal, hiring is then high when expected future cash flows from an additional worker are high, or when discount rates (expected stock returns) are low.

More important, the model makes the novel prediction that the negative hiring-expected return relation is steeper in industries that rely more on high skilled workers. This is the central prediction from the model that we test in the data. This result is also intuitive. Due to the intertemporal nature of a firms' hiring decision, the higher the labor adjustment costs are, the less elastically hiring responds to changes in the discount rate (all else equal, the risk adjusted benefit of hiring an additional worker goes down when the firm's discount rate goes up). Thus, when adjustment costs are higher, a given magnitude change in the hiring rate corresponds to a higher magnitude change in the discount rate. ${ }^{1}$

To test the model's asset pricing predictions, we estimate the cross-sectional relation between the firm's hiring rate and expected stock returns across industries which differ in the average skill level of its labor force (henceforth, high skill and low skill industries). Thus, consistent with the empirical evidence, we assume that the industry average skill level of its workers is positively correlated with the magnitude of labor adjustment costs in the industry. We then classify an industry to be a low or high skill industry based on the percentage of workers in that industry that are high skilled workers, using the Specific Vocational Preparation (SVP) index from the Dictionary of Occupational Titles (DOT), available from the Department of Labor, and data from the Bureau of Labor Statistics (BLS), Occupational Employment Statistics (OES) program. We compute the percentage of high skilled workers in an industry every year to keep track of technological change. Due to the availability of the labor skill data, our main asset pricing tests are then performed for the 1991 to 2012 period.

The main empirical findings can be summarized as follows. In firm-level panel OLS stock return predictability regressions using the firm's lagged hiring rate as a predictor, we show that the negative hiring-expected return relation is significantly steeper for firms in high skill industries than for firms in low skill industries. In the baseline regression, the

\footnotetext{
${ }^{1}$ Of course, in the model, hiring and discount rates are jointly determined in equilibrium, but this causal interpretation is useful to organize ideas.
} 
difference in the slope coefficient associated with the firm's lagged hiring rate in the low and high skill industries is both economically and statistically significant: a $20 \%$ increase in the firm's hiring rate (which roughly corresponds to a $20 \%$ increase in the size of the firm's workforce), is associated with a decrease of $-2.3 \%$ in firms' expected (future) stock return in the low skill industry, and with a decrease of $-3.9 \%$ in firm's expected return in the high skill industry. That is, the hiring-expected return negative relation is 1.7 times steeper in high skill industries than in low skill industries. This difference in the slope coefficients increases even more when we control for firm-fixed effects or for the effect of micro cap firms in the results, in which case the negative hiring-expected return relation can be 3.2 times steeper in high skill industries than in low skill industries.

The results from the firm-level panel OLS regressions are in general confirmed when we test the model's predictions using a portfolio approach. We construct five one-way sorted on firms' labor hiring rate portfolios separately in low and high skill industries. In the baseline portfolio analysis, we find that the hiring return spread, that is, the difference in average returns of the portfolio of firms with currently low hiring rates relative to the portfolio of firms with currently high hiring rates in the cross section, is considerably larger in high skill industries than in low skill industries. In low skill industries, the hiring return spread is about $2.7 \%$ per annum, and this value is only 1.1 standard errors from zero. In high skill industries, the hiring return spread is about $8.6 \%$ per annum, and this value is more than 2.7 standard errors from zero. Thus, the hiring return spread is about three times larger in high skill industries than in low skill industries.

To help establish the robustness of the findings we perform several additional analysis. First, we use international data for the G7 countries (France, Germany, Italy, UK, Canada, Japan, but exclude the U.S.) and show that the negative hiring-expected return relation is steeper (between 1.6 and 2.7 times steeper, depending on the specification) in high skill industries than in low skill industries in these countries as well. Second, we show that the inference from the firm-level panel OLS regressions is robust to the econometric procedure: we obtain similar results using Fama-MacBeth (1973) cross sectional regressions. Third, the main results hold when we extend the sample backwards to start in 1963 by assigning the average industry level labor skill measure between 1991 and 2001 to all the years between 1963 and 1991. Finally, the negative hiring-expected return relation remains steeper in high skill industries than in low skill industries even after controlling for several other return predictors, although this last analysis is outside the scope of the theoretical analysis. ${ }^{2}$

\footnotetext{
${ }^{2}$ In the online appendix, we show that our results are robust to using an alternative labor skill measure based on firm-level R\&D investment data, which we show to be positively correlated with our baseline industry-level labor skill measure. We show that the negative hiring-expected return relation is also steeper in industries that are more R\&D intensive (high skill industry) than in low R\&D intensive (low skill industry).
} 
The theoretical model makes several additional predictions which we also test in the data. The model predicts that the negative hiring-expected return relation is not explained by differential exposure to the market factor, that is, the unconditional capital asset pricing model (CAPM) fails, especially in industries characterized by high labor adjustment costs. The economic reason for this result is that the hiring return spread in the model is driven by firms' exposure to the aggregate adjustment cost shock. Because in the model the aggregate stock market is almost entirely driven by aggregate productivity shocks that are uncorrelated with the aggregate adjustment cost shock, the CAPM is unable to capture the difference in the risk of the hiring portfolios. The predicted failure of the CAPM is more pronounced in the high skill industry because the exposure of the hiring portfolios to the adjustment cost shock is proportional to the magnitude of the labor adjustment costs, which are higher in this industry. In addition, the mechanism in the model implies that the Sharpe ratio of the hiring spread portfolio should be higher in high skill industries.

Consistent with these predictions, we find that the unconditional CAPM cannot explain the hiring return spread in the high skill industry. The CAPM performs reasonably well in the low skill industry in which none of the portfolio's alphas are significant. In the high skill industry the CAPM generates large abnormal returns. In particular, the abnormal return of the low minus high hiring portfolio is economically large, $10.4 \%$ per annum, which is more than 3.1 standard errors from zero, and is even larger than the hiring return spread itself $(8.6 \%)$. The alpha of the hiring return spread portfolio in the high skill industry is 8.1 percentage points larger than the alpha of the hiring return spread in the low skill industry, and this difference is more than 2.5 standard errors from zero. Finally, the Sharpe ratio of the hiring spread portfolio is about two times larger in the high skill industry than in the low skill industry.

Naturally, labor-force heterogeneity may affect asset prices through other channels as well, not just due to differences in the labor adjustment cost channel that we examine in the baseline model. In an extended version of the model we thus consider the following two additional sources of labor-force heterogeneity, which are consistent with the evidence from previous studies: (i) differences in the economic environment (demand/TFP volatility) of the industries in which high skilled and low skilled workers operate, in particular, the fact that demand and/or productivity shocks are more volatile in high skill industries; and (ii) differences in the productivity and the wage rate process of high skilled and low skilled workers, in particular, the fact that the wage rate of high skilled workers is higher and smoother than the wage rate of low skilled workers. We show that while adding these additional features allows us to improve the model fit on several dimensions (especially for the fit of the model on the moments for real quantities), these features do not affect in a 
quantitatively important way the key testable predictions relating the firm's hiring rate and stock returns with different levels of labor skills that we obtain from the baseline model. This result suggests that differences in the adjustment costs of low and high skilled workers is a quantitatively important channel through which labor-force heterogeneity affects asset prices in financial markets.

The paper proceeds as follows. Section 2 discusses the related literature. Section 3 introduces labor-force heterogeneity in a neoclassical investment model with labor adjustment costs to obtain testable predictions and organize the empirical analysis. Section 4 describes the asset prices, accounting, and labor market data used in our empirical tests. Section 5 presents our main findings. Section 6 presents the results from several robustness analysis. Section 7 introduces other sources of labor-force heterogeneity in the baseline model. Finally, Section 8 concludes. A separate appendix with additional results and robustness checks is posted online.

\section{Related literature}

Our analysis assumes that the magnitude of labor adjustment costs is positively correlated with the worker's labor skill level. In addition, the analysis in the extended model investigates the impact of higher wage rigidity of high skilled workers on asset prices. These assumptions have theoretical and empirical support. Hamermesh (1993) reviews a set of direct estimates of the costs of adjusting labor, and shows evidence that it is more costly to replace a high skilled worker than a low skilled worker. ${ }^{3}$ More recently, Dube, Freeman, and Reich (2010), using a panel survey of California businesses in 2003 and 2008, establish that replacement costs are substantial relative to annual wages, vary positively with the worker's wage rate, and are higher for professional and managerial (high skilled) workers than for blue collar and manual labor workers (low skilled). Ochoa (2013), using data from the 1980 Employment Opportunities Pilot Projects (EOPP), finds that the cost of hiring is positively associated with labor skill of the new hire.

Lagakos and Ordonez (2011) show that wages are smoothed relatively more in high skill industries than in low skill industries. Parker and Vissing-Jorgensen (2009, 2010) show

\footnotetext{
${ }^{3}$ Additional empirical studies on the link between labor skills and magnitude of labor adjustment costs include: Oi (1962), Mincer (1962), Shapiro (1986), Pfan and Vespagen(1989), Button (1990), Hammermesh and Pfan (1996), Cappelli and Wilk, (1997), Dolfin (2006), Blatter, Muehlemann, Schenker (2012), among others. For additional theoretical analysis, see, for example, Acemoglu (2001) and Caballero (2007). The importance of labor adjustment costs is consistent with the theoretical work by Diamond (1982), Mortensen (1982), and Pissarides (1985), and with the empirical work surveyed in Hamermesh and Pfann (1996) and Bond and Van Reenen (2007).
} 
that the cyclicality of wages is higher for low-income (less skilled) households than for highincome (more skilled) households at all levels of the income distribution except for the top $1 \%$, whose wages are much more cyclical than average. Additional studies documenting the higher wage rigidity of high skilled workers include Campbell (1997), Caju, Fuss and Wintr (2007), among others.

Several recent studies emphasize the importance of labor frictions (labor adjustment costs, search frictions, and/or wage rigidities) to understand asset prices, and the dynamics of real macroeconomic variables. A non-comprehensive list of contributions is, for aggregatelevel analysis, Danthine and Donaldson (2002), Uhlig (2007), Merz and Yashiv (2007), Petrosky-Nadeau, Zhang, and Khuen (2013), Favilukis and Lin (2015); for firm-level analysis, Bloom (2009), BLB (2014), Khuen, Simutin and Wang (2014), Donangelo, Gourio, and Palacios (2015). None of these papers consider explicitly heterogeneity in the labor-force as we have here. Hall (2014) shows that in an economy with search and matching frictions, firms' hiring decisions are affected by movements in discount rates, consistent with our approach. This mechanism helps explain the high and persistent aggregate-level unemployment rates during recessions. His work does not investigate the importance of the mechanism for equilibrium risk premiums in the cross section.

The focus on labor heterogeneity is related to early work by Kydland (1984), and more recent work by Lustig, Syverson, and Van Nieuwerburgh (2011), Eisfeldt and Papanikolaou (2013), Ochoa (2013), and Donangelo (2014). Kydland (1984) incorporates labor-force heterogeneity in an otherwise standard real business cycle model and shows that this extension helps improve the fit of the model to the data. His work does not look at asset prices. Lustig, Syverson, and Van Nieuwerburgh (2011) show that technological change starting from 1970s stimulates the accumulation of firms' organizational capital which in turn leads to the secular change in the U.S. labor market reallocations. Eisfeldt and Papanikolaou (2012) show that firms with more organizational capital are riskier (i.e., have higher average stock returns) than firms with less organizational capital. Because organizational capital is embodied in the firm's labor force, their findings show that the characteristics of the labor force have an impact on firms' risk, a finding that is consistent with the main findings that we report here.

In a contemporaneous paper, Ochoa (2013) documents that firms in high labor skill industries have higher returns than firms in low skilled labor industries. In contrast with Ochoa (2013), our main empirical analysis focuses on the negative hiring-expected return relation across industries with different labor skills levels, consistent with the approach in the neoclassical theory of investment literature (see, for example, Li and Zhang (2010), for a similar approach in the context of differences in investment (not hiring) frictions across 
firms). Donangelo (2014) shows that differences in labor mobility across industries, that is, the flexibility of workers to walk away from employers in response to better opportunities, leads to differences in risk premiums in the cross section. Our analysis focuses on a different characteristic of the labor-force, differences in the average skill of workers. Thus, our work is also related to the empirical literature on asset pricing which explores the predictability of firm characteristics for stock returns (Fama and French, 2008, provide a survey of this literature). We link the characteristics of the labor force (skilled labor) to expected returns, thus helping us to understand the economic determinants of equilibrium risk premiums in the cross section.

The approach in this paper is also related to the literature that studies asset prices in production economies (see, for example, Kogan (2001 and 2004), Zhang (2005), Tuzel (2009), Imrohoroglu and Tuzel (2012), and Kogan and Papanikolaou (2013 and 2014)). In most of these studies labor is assumed to be an homogenous input across firms. Finally, our work is related to studies on the importance of human capital, a characteristic of the labor force that is closely related to labor skills, for understanding equilibrium asset prices. References on the relationship between human capital and asset returns go as far back as Mayers (1972) and Fama and Schwert (1977). More recent work includes Santos and Veronesi (2006), Lustig and Van Nieuwerburgh (2008), Betermier, Jansson, Parlour and Walden (2012), Berk and Walden (2013), and Palacios (2015). Different from the work in this literature, we link firmlevel labor variables to asset prices through the lens of a neoclassical model of investment, thus focusing on the characteristics of the firms' technologies and on its role to determine the properties of the firm's endogenous cash flows.

\section{Hypotheses development}

To guide the empirical analysis, we introduce labor-force heterogeneity in the neoclassical model of investment proposed in BLB (we refer the reader to BLB for justification of the standard model ingredients). We consider two different industries, which differ in the type of workers used in the production process. The technology in the first industry uses high skilled workers (high skill industry), while the technology in the second industry uses low skilled workers (low skill industry). ${ }^{4}$ Here, we describe the general model which allows for several forms of labor-force heterogeneity: differences in labor adjustment costs, worker's productivity, wage rate, and productivity shocks in the two industries. We then solve for

\footnotetext{
${ }^{4}$ We focus on one type of worker in each industry for tractability and without loss of generality. In practice, firms' use both type or workers, which could generate interesting substitution effects. As we discuss in the data section below, however, the fraction of high skill workers used in each industry is very persistent in the data, suggesting that this substitution effect is not empirically very relevant.
} 
equilibrium asset prices in the two industries in restricted versions of the model to understand the incremental impact of each form of labor-force heterogeneity on asset prices.

\subsection{Economic environment}

Within a given industry $i=$ low skill, high skill, the model is similar to the homogenous economy of BLB. In each industry, there is a large number of firms that produce a homogeneous good.

\subsubsection{Technology}

We focus on the optimal production decision problem of one firm in industry $i$ (we suppress any firm-specific subscripts to save on notation). The firm uses capital inputs $K_{t, i}$ and labor inputs $N_{t, i}$ to produce output $Y_{t, i}$, according to the following constant elasticity of substitution (CES) technology:

$$
Y_{t, i}=Z_{t, i} X_{t}^{1-\theta}\left[\alpha K_{t, i}^{1-1 / \phi}+(1-\alpha)\left(\lambda_{i} N_{t, i}\right)^{1-1 / \phi}\right]^{\theta /(1-1 / \phi)}
$$

in which $\alpha>0$ controls the relative weight of the two inputs in the production process, $0<\theta \leq 1$ is the degree of returns to scale, and the parameter $\phi>0$ controls the elasticity of substitution between physical capital and the total labor stock. When $\phi \rightarrow 1$ the CES aggregator collapses to the Cobb-Douglas case, when $\phi \rightarrow+\infty$ the two inputs are perfect substitutes, and when $\phi \rightarrow 0$ the two inputs are perfect complements (Leontief). $X_{t}$ is aggregate productivity, and $Z_{t, i}$ is firm-specific productivity, the source of cross-sectional heterogeneity within each industry. $\lambda_{i}$ controls the average productivity of one worker in industry $i$.

The law of motion of the firm's total labor force $N_{t, i}$ is given by

$$
N_{t+1, i}=\left(1-\delta_{n}\right) N_{t, i}+H_{t, i} \quad 0<\delta_{n}<1
$$

in which $\delta_{n}$ is the (constant) quit rate, the rate at which workers leave the firm for voluntary reasons, and $H_{t, i}$ is gross hires, which can be positive (hire) or negative (fire).

Similarly, the law of motion of the firm's capital stock $K_{t, i}$ is given by

$$
K_{t+1, i}=\left(1-\delta_{k}\right) K_{t, i}+I_{t, i} \quad 0<\delta_{k}<1
$$

where $\delta_{k}$ is the capital depreciation rate, and $I_{t, i}$ is gross investment, which can be positive (investment) or negative (disinvestment). 
Both labor hiring and capital investment are subject to asymmetric nonconvex and convex adjustment costs. The labor adjustment costs include training and screening of new workers, advertising of job positions, disruption costs (output that is lost through time taken to readjust the schedule and pattern of production) and separation costs (for example, severance pay). Labor adjustment costs are specified by the following function:

$$
C N_{t, i}^{\text {adj }}=\left\{\begin{array}{lll}
b_{n, i}^{+} Y_{t, i}+\frac{c_{n, i}^{+}}{2}\left(\frac{H_{t, i}}{N_{t, i}}\right)^{2} N_{t, i} & \text { if } & H_{t, i}>0 \\
0 & \text { if } & H_{t, i}=0 \\
b_{n, i}^{-} Y_{t, i}+\frac{c_{n, i}^{-}}{2}\left(\frac{H_{t, i}}{N_{t, i}}\right)^{2} N_{t, i} & \text { if } & H_{t, i}<0
\end{array}\right.
$$

in which $\theta_{n, i} \equiv\left[c_{n, i}^{+}, c_{n, i}^{-}, b_{n, i}^{+}, b_{n, i}^{-}\right]>0$ is a vector of constants that controls the size of labor adjustment costs in industry $i$.

Capital adjustment costs include planning and installation costs, learning the use of new equipment, or the fact that production is temporarily interrupted. The capital adjustment costs are specified by the following function:

$$
C K_{t, i}^{\mathrm{adj}} \equiv I_{t, i}+\left\{\begin{array}{lll}
b_{k}^{+} Y_{t, i}+\frac{c_{k}^{+}}{2}\left(\frac{I_{t, i}}{K_{t, i}}\right)^{2} K_{t, i} & \text { if } & I_{t, i}>0 \\
0 & \text { if } & I_{t, i}=0 \\
b_{k}^{-} Y_{t, i}+\frac{c_{k}^{-}}{2}\left(\frac{I_{t, i}}{K_{t, i}}\right)^{2} K_{t, i} & \text { if } & I_{t, i}<0
\end{array}\right.
$$

in which $\theta_{k} \equiv\left[c_{k}^{+}, c_{k}^{-}, b_{k}^{+}, b_{k}^{-}\right]>0$ is a vector of constants that controls the size of the capital adjustment costs. The capital adjustment cost parameters are the same in the two industries because our focus is on labor-force heterogeneity. Note that we include investment expenditures $\left(I_{t, i}\right)$ in this specification of capital adjustment costs.

Adjustment costs are stochastic. The total adjustment cost function of the firm is given by

$$
\Psi_{t, i}=\frac{\left[C N_{t, i}^{\mathrm{adj}}+C K_{t, i}^{\mathrm{adj}}\right]}{S_{t}},
$$

in which $S_{t}$ is a stochastic variable that captures changes in the aggregate cost of adjusting the inputs. We refer to $S_{t}$ as an adjustment cost wedge and shocks to this wedge as an adjustment cost shock.

Finally, the firm also incurs fixed operating costs of production that are independent of firm size, which are captured by $F_{t, i}=f_{i} X_{t}$, with $f_{i}>0$. We scale the fixed operating costs by aggregate productivity to allow for growth in the economy. 


\subsubsection{Stochastic processes}

Aggregate productivity follows a random walk process with a drift

$$
\Delta x_{t+1}=\mu_{x}+\sigma_{x} \varepsilon_{t+1}^{x},
$$

in which $x_{t+1}=\log \left(X_{t+1}\right), \Delta$ is the first-difference operator, $\varepsilon_{t+1}^{x}$ is an independently and identically distributed (i.i.d.) standard normal shock, and $\mu_{x}$ and $\sigma_{x}$ are the average growth rate and conditional volatility of aggregate productivity, respectively.

Firm-specific productivity follows the AR(1) process

$$
z_{t+1, i}=\bar{z}\left(1-\rho_{z}\right)+\rho_{z} z_{t, i}+\sigma_{z, i} \varepsilon_{t+1, i}^{z},
$$

in which $z_{t+1, i}=\log \left(Z_{t+1, i}\right), \varepsilon_{t+1, i}^{z}$ is an i.i.d. standard normal shock that is uncorrelated across all firms in the economy and independent of $\varepsilon_{t+1}^{x}$, and $\bar{z}, \rho_{z}$, and $\sigma_{z, i}$ are the mean, autocorrelation, and conditional volatility of firm-specific productivity, respectively.

The aggregate adjustment cost wedge follows the AR(1) process

$$
s_{t+1}=\rho_{s} s_{t}+\sigma_{s} \varepsilon_{t+1}^{s},
$$

in which $s_{t+1}=\log \left(S_{t+1}\right), \varepsilon_{t+1}^{s}$ is an i.i.d. standard normal shock that is independent of all the other shocks in the economy, and $\rho_{s}$ and $\sigma_{s}$ are the persistence and conditional volatility of the aggregate adjustment cost wedge, respectively.

Given the focus on the production side of the economy, we directly specify the stochastic discount factor $M_{t, t+1}$ (used to value the firm's cash flows arriving in period $t+1$ ), as well as the equilibrium stochastic wage rate, without explicitly modeling the consumer's problem. Firms are competitive and take these prices as given. The stochastic discount factor (marginal utility) is a function of the two aggregate shocks in the economy and is given by

$$
M_{t, t+1}=\exp \left(-r_{f}\right) \frac{\exp \left(-\gamma_{x} \Delta x_{t+1}-\gamma_{s} \Delta s_{t+1}\right)}{\mathbb{E}_{t}\left[\exp \left(-\gamma_{x} \Delta x_{t+1}-\gamma_{s} \Delta s_{t+1}\right)\right]},
$$

in which $r_{f}$ is the constant $(\log )$ risk-free rate, and $\gamma_{x}>0$ and $\gamma_{s}<0$ are the loadings of the stochastic discount factor on the two aggregate shocks, and the operator $\mathbb{E}_{t}[$.$] represents$ the expectation over all states of nature at time $t$. The sign of the loadings of the stochastic discount factor on the two aggregate shocks follows from previous studies. Most equilibrium models (see, for example, Jermann, 1998) imply $\gamma_{x}>0$, that is, low productivity states are associated with low output and thus low consumption and high marginal utility. The specification $\gamma_{s}<0$ is consistent with the analysis in BLB, and with the theoretical and 
empirical literature on the impact of investment-specific shocks on asset prices (for example, Papanikolaou, 2011, and Kogan and Papanikolaou, 2013 and 2014).

The real wage rate is an increasing function of the aggregate productivity shock and is given by

$$
W_{t, i}=\tau_{1, i} \exp \left(\tau_{2, i} \Delta x_{t}\right)
$$

with $\tau_{1, i}, \tau_{2, i}>0$. In this specification, $\tau_{1, i}$ is a scaling factor, and the parameter $\tau_{2, i}$ controls the cyclicality and volatility of the wage rate in each industry. ${ }^{5}$

\subsubsection{Firm's maximization problem}

All firms in the economy are assumed to be all-equity financed, so we define

$$
D_{t, i}=Y_{t, i}-W_{t, i} N_{t, i}-\Psi_{t, i}-F_{t, i}
$$

to be the dividend distributed by the firm to the shareholders. The dividend consists of output $Y_{t, i}$, less the wage bill $W_{t, i} N_{t, i}$, total adjustment costs $\Psi_{t, i}$, which includes the purchase cost of investment, and fixed operating costs $F_{t, i}$. A negative dividend is considered as an equity issuance.

Define the vector of state variables as $\mathbb{S}_{t, i}=\left(K_{t, i}, N_{t, i}, x_{t}, z_{t, i}, s_{t}\right)$, and let $V\left(\mathbb{S}_{t, i}\right)$ be the cum-dividend market value of the firm in period $t$. The firm makes hiring $H_{t, i}$ and investment $I_{t, i}$ decisions to maximize its cum-dividend market value by solving the problem

$$
V\left(\mathbb{S}_{t, i}\right)=\max _{\left\{I_{t+j, i}, K_{t+j+1, i}, H_{t+j, i}, N_{t+j+1, i}\right\}_{j=0}^{\infty}}\left\{\mathbb{E}_{t}\left[\sum_{j=0}^{\infty} M_{t, t+j} D_{t+j, i}\right]\right\},
$$

subject to the labor and capital accumulation equations (2) and (3) and the flow of funds constraint (12) for all dates $t$.

\subsection{Testable predictions}

The goal of the theoretical analysis is to understand how labor-force heterogeneity affects asset prices in the cross section. Consistent with standard neoclassical theory of investment (see introduction section), we focus on the model's predicted link between the firm's level hiring rate and discount rate (risk premia), and how this link varies with the type of workers used in the production process across heterogenous industries. This link is conveniently

\footnotetext{
${ }^{5}$ For simplicity, as in BLB, we specify the wage rate process to be a function of one aggregate shock only (TFP shocks). Consistent with the analysis in BLB (internet appendix), we obtain very similar results to those reported here when we specify the wage rate process to be a function of both TFP and adjustment cost shocks, at least for reasonable calibrations of the model (results available upon request).
} 
summarized by examining the properties of portfolios sorted on the firms' current hiring rate in artificial data generated from the model, and examine the properties of the portfolio's average realized returns. ${ }^{6}$ In particular, we focus on the properties of the low minus high hiring $(\mathrm{HN})$ portfolio, which we refer to as the hiring spread portfolio.

\section{[Insert Table 1 here]}

To obtain the model's predictions, we start by calibrating the model using the same parameter values used in BLB. The parameters are reported in Table 1, and were chosen to match 25 aggregate- and firm-level moments of asset prices and real quantities (see Table 6 in BLB). This model generates a sizeable equity premium (about $4.8 \%$ per annum), a large value premium (about 5.5\% per annum), a smooth risk free rate, and matches key properties of the aggregate wage rate, aggregate profits, and several properties of the firmlevel investment and hiring rates both in the time series and in the cross-section. To obtain the model implied moments we solve the endogenous variables numerically. Appendix A-1 provides a description of the solution algorithm (value function iteration) and the numerical implementation of the model.

Naturally, the homogenous economy studied in BLB does not generate any differences in the hiring return spread across industries because all firms are ex-ante identical in that model. Thus, we now introduce labor-force heterogeneity in the model by examining the model implied moments generated by alternative calibrations. As discussed in the introduction section, the key difference between the low and high skill industry that we focus on in the baseline specification of the model, is the difference in the magnitude of the labor adjustment costs in the two industries. To that end, we compare two different calibrations of the model which differ only in the size of the labor adjustment cost parameters summarized in the vector $\theta_{n, i} \cdot{ }^{7}$ In the first calibration, we set $\theta_{n, i}$ to be small, in particular, we set each element in the parameter vector $\theta_{n, l o w}$ to be $1 / 6$ of the baseline parameters used in BLB. This calibration corresponds to a low skill industry. In the second specification, we set $\theta_{n, i}$ to be high, in particular, we set each element in the parameter vector $\theta_{n, \text { high }}$ to be 1.25 times larger than the baseline parameters in BLB. This calibration corresponds to a high skill industry. The comparison between these two specifications (and its comparison with the BLB economy)

\footnotetext{
${ }^{6}$ Following Fama and French (1993), we construct the hiring portfolios using data generated from the model as follows. At the end of June of year $t$, we sort all firms into five portfolios based on the firm's hiring rate at the end of year $t-1$. The hiring breakpoints used to allocate firms into portfolios are the quintiles of the hiring rate cross-sectional distribution of all firms. Once the portfolios are formed, their value-weighted returns are tracked from July of year $t$ to June of year $t+1$. The procedure is repeated at the end of June of year $t+1$.

${ }^{7}$ For technical reasons (avoid negative firm values), the operating fixed cost parameter $f_{i}$ also varies across calibrations, but this feature has no qualitatively effects on our results.
} 
can be interpreted as a comparative statics exercise, which allows us to obtain qualitative predictions from the model in a simple manner (the exact scalings of the labor adjustment costs were not calibrated hence this analysis is mostly qualitative). We provide a more formal quantitative analysis of this calibration in Section 7 below, in particular, we discuss the fit of the model on other moments, such as the hiring and investment rate volatilities.

\section{[Insert Table 2 Here]}

Table 2, column 2 (Adj. cost) reports the main testable asset pricing predictions from the baseline version of the model in which the only difference across the two industries is the magnitude of the labor adjustment cost parameters. Rows 1 and 2 show that the average hiring return spread (low minus high hiring) in the two industries is positive, that is, as in BLB (reported in column 1), the model predicts a negative relation between firms' current hiring rate and future stock returns (discount rate). This is a result that follows from standard neoclassical theory of investment (see, for example, Abel and Blanchard, 1986), applied to labor. Intuitively, optimal labor hiring by firms is high when the expected future marginal profitability of labor inputs is high, or when the discount rate (cost of capital), used to value the future marginal profitability of labor is low, or both. Thus, the link between labor hiring and expected stock returns (discount rate) is negative, consistent with the evidence in previous studies. ${ }^{8}$

The first new theoretical finding is reported in rows 1 and 2, which shows that the predicted hiring return spread is larger in high skill industries than in low skill industries. In these calibrations, the hiring return spread is $5.3 \%$ per annum in the high skill industry versus $1.2 \%$ per annum in the low skill industry. In the baseline BLB (column 1), the hiring return spread is $4.4 \%$, which is between the previous two values. Thus, the hiring return spread is increasing in the size of the labor adjustment cost parameters. Given the importance of this central prediction in our analysis, we state it explicitly as prediction 1 (P1).

P1: The negative hiring-expected return relation is steeper in industries that rely more on high skilled workers.

The economic intuition behind the result in P1 is as follows. When hiring is close to frictionless, $\theta_{n} \rightarrow 0$, hiring becomes infinitely elastic to changes in the discount rate (risk premium). With hiring frictions, $\theta_{n}>0$, hiring entails costs, and these costs are increasing in the firm's hiring rate. As such, hiring is less elastic to the discount rate. The crucial

\footnotetext{
${ }^{8}$ Of course, in the model, hiring and expected stock returns are jointly determined, but this causal interpretation is useful to organize ideas.
} 
observation for our empirical tests is that the magnitude of this elasticity decreases with the size of $\theta_{n}$. The higher $\theta_{n}$ is, the less elastically hiring responds to changes in the discount rate. That is, the higher $\theta_{n}$ is, a given magnitude change in hiring rate corresponds to a higher magnitude change in the discount rate. This effect means that the negative hiringexpected return relation is steeper for firms with high labor adjustment costs, which we identify as firms in industries that rely more on high skill labor, than for firms with low hiring adjustment costs. Our main empirical analysis is centered around this result.

Table 2 shows two additional asset pricing predictions from the model. In rows 3 and 4, the model predicts that the Sharpe ratio of the hiring spread portfolio is higher in the high skill industry. In these calibrations, the Sharpe ratio of the hiring spread portfolio is 1.1 at the annual frequency in the high skill industry versus 0.2 in the low skill industry (in the baseline BLB economy, the Sharpe ratio is 1.05). That is, the relatively higher hiring return spread in the high skill industry is not simply a compensation for higher return volatility. This is the second prediction from the model (P2).

P2: The Sharpe ratio of the hiring spread portfolio is higher in industries that rely more on high skilled workers

The previous result P2 is interesting because it suggests that the hiring return spread is not driven by a standard operating leverage effect, a popular alternative mechanism in the cross sectional asset pricing literature (for example, Zhang, 2005, shows that operating leverage can generate a large value spread in a one aggregate-shock model). This is because operating leverage, similar to financial leverage, generates a positive link between average returns and return volatility, and hence no (or very small) variation in Sharpe ratios across portfolios. As we discuss below, the hiring return spread is driven by the two aggregate shock structure of the model.

Finally, the model has implications for tests of asset pricing models. Several studies emphasize the importance for structural models to match the failure of the capital asset pricing model (CAPM) (see, for example, Lettau and Wachter, 2007; and Kogan and Papanikolaou, 2013), because this failure provides an important set of moments that help distinguish between alternative economic mechanisms that generate risk dispersion in the cross section (for example, one- versus two-aggregate shock models). Rows 5 and 6 in Table 2 show that, consistent with BLB, the model predicts that the hiring return spread is not explained by exposure to the market factor: the unconditional CAPM fails, and the model generates large CAPM alphas. ${ }^{9}$ The novel prediction here is that the failure of the CAPM

\footnotetext{
${ }^{9}$ To test the CAPM in the model, we run monthly time-series regressions of the excess returns of each hiring portfolio on a constant and the excess returns of the market portfolio (market). To avoid taking a stand on the fraction of firms in each low and high skill industry, we take the market portfolio in each
} 
is significantly more pronounced in the high skill industry. In these calibrations, the CAPM alpha of the hiring spread portfolio in the high skill industry is $7.2 \%$ per annum, but is only $2.8 \%$ per annum in the low skill industry (in the baseline BLB, the CAPM alpha of the hiring spread portfolio is $5.2 \%$ ), a difference in CAPM alphas of about $4.2 \%$ per annum. This is the third prediction from the model (P3).

P3: The CAPM alpha of the hiring spread portfolio is higher in industries that rely more on high skilled workers.

The failure of the unconditional CAPM in the model, especially in the high skill industry, is due to the interaction of the adjustment cost shock and the labor adjustment costs. To understand this result, note that the two aggregate shock structure of the model implies that the equilibrium risk premia (expected excess returns) of any asset in the economy is given by the following standard asset pricing equation:

$$
\mathbb{E}_{t}\left[r_{t+1}^{e}\right]=\lambda_{x} \times \beta^{x}+\lambda_{s} \times \beta^{s}
$$

in which $r_{t+1}^{e}=R_{t+1}^{s}-R_{f}$ is the stock excess return, $R_{f} \equiv \exp \left(r_{f}\right)=\mathbb{E}_{t}\left[M_{t, t+1}\right]^{-1}$ is the gross risk-free rate, $\lambda_{x}=\gamma_{x} \operatorname{Var}\left(\Delta x_{t+1}\right)$ and $\lambda_{s}=\gamma_{s} \operatorname{Var}\left(\Delta s_{t+1}\right)$ are the price of risk of the aggregate productivity shock and aggregate adjustment cost shock, respectively, and $\beta^{x}=\operatorname{Cov}\left(r_{t+1}^{e}, \Delta x_{t+1}\right) / \operatorname{Var}\left(\Delta x_{t+1}\right)$ and $\beta^{s}=\operatorname{Cov}\left(r_{t+1}^{e}, \Delta s_{t+1}\right) / \operatorname{Var}\left(\Delta s_{t+1}\right)$ are the sensitivities (betas) of the firm's excess stock returns with respect to the two aggregate shocks in the economy. The model generates a spread in the average returns of the hiring portfolios because high hiring firms in the model are more exposed (higher adjustment cost shock beta) to the aggregate adjustment cost shocks, which carry a negative price of risk in equilibrium. But in this model, the overall stock market (or industry) return is almost entirely driven by aggregate productivity shocks that are uncorrelated with the aggregate adjustment cost shock. ${ }^{10}$ As a result, the CAPM fails to explain the cross sectional variation of the hiring portfolios because the overall stock market return is barely correlated with the aggregate adjustment cost shock (aggregate productivity shocks and the adjustment cost shocks are uncorrelated). The novel insight here is that because the exposure of the hiring portfolios

industry to be the overall industry level return. This approach has no impact on the qualitative results because the industry level return is mostly driven by the aggregate TFP shock.

${ }^{10}$ In the baseline model, almost all of the variation of the aggregate stock market return is driven by shocks to aggregate productivity. Across panels, a multivariate time-series regression of the aggregate stock market (or industry) return on the two risk factors has an average regression $R^{2} \approx 98 \%$, a univariate regression on the aggregate productivity shock has an average regression $R^{2} \approx 88 \%$, but a univariate regression on the aggregate adjustment cost shock has an average regression $R^{2} \approx 10 \%$ (results not tabulated). Thus, because the aggregate stock market (or industry) return is mostly driven by the aggregate productivity shock, the market factor alone fails to capture the differential exposure of the hiring portfolios to the adjustment cost shock. 
to the adjustment cost shock is proportional to the magnitude of the labor adjustment costs (the aggregate adjustment cost shock affect labor adjustment costs as a proportional shift of the adjustment cost schedule) the model predicts that the failure of the CAPM is more pronounced in the high skill industry because of its higher labor adjustment costs.

In this section, we examined the impact of difference in the hiring and firing costs of high skilled and low skilled workers on asset prices, which we now test in the data. These are robust predictions from the model. In Section 7 below, we examine the model implications for other moments (real quantities), and the the impact of other additional realistic features of the labor-force heterogeneity, and find that the predictions P1 to P3 also hold in more general versions of the model.

\section{Data}

In this section we describe the data (asset prices and accounting variables), and the industrylevel labor skill variable used in our empirical tests. We also report the characteristics of a typical firm in each industry.

\subsection{An industry-level labor skill measure}

The key labor skill measure used in our empirical analysis is the variable Skill, which is the fraction of high skilled workers in a given industry. We use two data sources to compute this measure. The first data source is the Dictionary of Occupational Titles (DOT): Revised Fourth Edition, 1991 from U.S. Department of Labor. ${ }^{11}$ DOT includes the information on Specific Vocational Preparation (SVP), which measures the amount of lapsed time required by a typical worker to learn the techniques, acquire the information, and develop the facility needed for average performance in a specific job-worker situation (Appendix A-2 describes the SVP index in more detail). The value of SVP ranges from 1 to 9 , where $\mathrm{SVP}=1$ corresponds to the lowest preparation, and SVP $=9$ corresponds to the highest preparation of over 10 years. We define a high skill occupation if its SVP index is equal to or greater than 7 (this corresponds to an occupation that requires over 2 years of preparation), and low skill otherwise. ${ }^{12}$

\footnotetext{
${ }^{11}$ The data for 1991 DOT are obtained from the Inter-university Consortium for Political and Social Research (ICPSR) Study No 6100 v.1 (DOI:10.3886).

${ }^{12}$ Our labor skill measure is based on Donangelo (2009), who first examined the link between this measure and asset prices. But the data sources used to compute this measure are different. Our primary dataset for the occupational level labor skill is from DOT, whereas Donangelo (2009) uses data from the Occupational Information Network (O*NET). In 1998, the O*NET supersedes Dictionary of Occupational Titles with current information that can be accessed online or through a variety of public and private sector career and
} 
Next, we compute the Skill variable for each industry by calculating the percentage (across all occupations) of workers in the industry that belong to a high skill occupation. We focus on this measure due to its simplicity and obvious interpretation. ${ }^{13}$ The data on the number of workers by occupation in each industry is from the Bureau of Labor Statistics (BLS), Occupational Employment Statistics (OES) program. The data is available since 1988 except in 1996 when OES did not conduct a survey. Each industry was surveyed every three years before 1996 and every year starting from 1997. Following Donangelo (2014), we use the same industry data for three consecutive years to ensure continuous coverage of the full set of industries in early years, which imposes a constraint on the beginning of our tradable sample period which is $1991 .{ }^{14}$ We define an industry using three-digit Standard Industrial Classification (SIC) codes until 2002, and four-digit North American Industry Classification System (NAICS) codes after 2002.

To help understand the Skill variable, Table 3 reports the top 10 (Panel A) and bottom 10 (Panel B) industries sorted on average labor skill in 2012. In this year, there are a total of 290 NAICS industries. Computer related industries are classified as high skill industries. We also note that health care related industries rank very high as well, although they are not in the top 10. Restaurants and other eating places, clothing stores, and shoe stores are low skill industries. The ranking conforms with our priors regarding the degree of required labor skills across these industries.

\section{[Insert Table 3 Here]}

\subsection{Asset prices and accounting data}

Most of the empirical tests are based on data for U.S. publicly traded firms. As a robustness check, we also test the main predictions from the model using international data for the G7 countries (France, Germany, Italy, UK, Canada, Japan, and U.S.).

labor market information systems. We use DOT instead of O*NET to maximize the sample size (start in 1991) while making sure that our investment strategy is tradable (O*NET data is available only after 1998).

${ }^{13}$ We note that the results reported here are robust to the use of other industry level measures of labor skills. For example, when we use the industry-level average across all SVPs, we obtain similar results to those reported here. Also, when we use a measure of the average level of education of the workers in a given industry, we obtain again similar results (results available upon request).

${ }^{14}$ For instance, the 1988 OES data covers only industries with SIC codes between 4000 and 5999 and certain industries with SIC codes above 8000. The 1989 OES data mainly covers SIC codes between 2000 and 3000. The 1990 OES data mainly covers industries with SIC codes 1000-1999, 6000-7999, and some industries above 8000. In addition, due to the difference in the classification of occupations, we use a crosswalk table that relates the older DOT codes to the new Standard Occupational Code (SOC). The crosswalk table is obtained from the Department of Education (https://www2.ed.gov/rschstat/eval/rehab/support/docsoc.xls). In addition, since the OES survey adopts the 2010 SOC classification starting from 2010, we also use a crosswalk table that relates the 2010 SOC codes to 2000 SOC codes for OES data since year 2010. 
U.S. data: Monthly stock returns are from the Center for Research in Security Prices (CRSP), and accounting information is from the CRSP/Compustat Merged Annual Industrial Files. The benchmark tradable sample is from July 1991 to December 2012. As standard, we exclude firms whose primary standard industry classification (SIC) is between 4900 and 4999 (regulated firms). We require a firm to have a fiscal year-end in the last quarter of the year, to roughly align the accounting data across firms (results are nearly identical if we require a December fiscal-year-end). We include firms with common shares $(\mathrm{SHRCD}=10$ and 11$)$ and firms traded on NYSE, AMEX, and NASDAQ (EXCHCD=1,2, and 3). We correct for the delisting bias following the approach in Shumway (1997). Finally, the data for the market factor (MKT) used in the tests of the unconditional capital asset pricing model (CAPM) is from Kenneth French's Web page.

We are interested in examining the relation between the firm-level hiring rate with future stock returns across industries with different levels of labor skill. We construct the hiring rate as in Davis, Faberman, and Haltiwanger (2006) and Bloom (2009). The firm-level hiring rate is given by $\mathrm{HN}_{t}=\mathrm{H}_{t} /\left(0.5 \times\left(\mathrm{N}_{t-1}+\mathrm{N}_{t}\right)\right)$, in which the number of employees $\left(\mathrm{N}_{t}\right)$ is given by Compustat data item EMP, and net hiring $\left(\mathrm{H}_{t}\right)$ is given by the change in the number of employees in year $t$ from year $t-1\left(\mathrm{H}_{t}=\mathrm{N}_{t}-\mathrm{N}_{t-1}\right)$. By construction, this measure of labor hiring is symmetric around zero and bounded between $\pm 200 \%$.

We also keep track of the following accounting variables. Following Bloom (2009), the firm-level investment rate is given by $\mathrm{IK}_{t}=\mathrm{I}_{t} /\left(0.5 \times\left(\mathrm{K}_{t-1}+\mathrm{K}_{t}\right)\right)$, in which the physical capital stock $\left(\mathrm{K}_{t}\right)$ is given by data item PPENT (net property plant and equipment), and physical capital investment $\left(\mathrm{I}_{t}\right)$ is given by Compustat data item CAPX (capital expenditures) minus SPPE (sales of property, plant, and equipment). Missing values of SPPE are set to zero. Market equity (size) is price times shares outstanding at the end of December of $t$, from CRSP. Age is the firm age measured as the number of years since the firm is included in CRSP. Lev is book-leverage. ${ }^{15}$ The book-to-market equity ratio (BM) is the ratio of the firm's book equity to market equity, computed as in Fama and French (1993). Firms' sales are given by data item SALE. Real sales growth rate ( $\Delta$ Sales) is thus measured by the ratio of the change in the sales from year $t-1$ to year $t$ to the sales in year $t-1$, deflated by the consumer price index. The firm's capital to labor ratio is given by the log of the ratio of the firms physical capital stock $\left(\mathrm{K}_{t}\right)$ deflated by the consumer price index, to the number of employees. Research and development (R\&D) intensity is given by data

\footnotetext{
${ }^{15}$ Following Liu, Whited, and Zhang (2009), book leverage is given by

$$
\mathrm{Lev}=(\mathrm{DLTT}+\mathrm{DLC}) /(\mathrm{DLTT}+\mathrm{DLC}+\mathrm{ME})
$$

in which: DLTT is Long-Term Debt - Total, DLC is Debt in Current Liabilities - Total, and ME is market equity.
} 
item XRD divided by SALE.

The industry-level annual wage rate data are calculated for a subsample of industries from the National Bureau of Economic Research and U.S. Census Bureau's Center for Economic Studies (NBER-CES) Manufacturing Industry Database. This database contains annual industry-level data from 1958-2009 on output, employment, payroll and other input costs, investment, capital stocks, TFP, and various industry-specific price indexes. We define the wage rate for each industry as the ratio of the total payroll to total employment for that industry. The real wage rate is then computed as the ratio of the nominal wage and the consumer price index.

We exclude from the sample the firm-year observations with missing or negative capital stock data, missing number of employees, number of employees less than 50, missing capital expenditures data, and missing labor skill data. The final U.S. sample includes a total of 53,233 firm-year observations.

International data: The accounting data for the G7 countries is from Compustat Global Fundamentals Annual file and the key variables are defined in the same way as in the U.S. sample. The security data is from Compustat Global Security Daily. The sample period of our data ranges from 1992 to 2012 but the exact starting year varies by country. We keep the primary issue of each company (IID=PRIROW) and we only include common stocks $(\mathrm{TPCI}=0)$. We convert all prices at the end of each month into U.S. dollars and calculate the stock return in month $t$ taking into account any change in the number of shares outstanding. ${ }^{16}$

In contrast to the high quality of the U.S. data, the Compustat global data has significantly more measurement errors. Following Ince and Porter (2006), Hou, Karolyi, and Kho (2011), and others, we apply the following filters to deal with potential errors in the data. First, we set monthly returns $R_{t}, R_{t-1}$ as missing if $R_{t}$ or $R_{t-1}$ is above $300 \%$, and $\left(1+R_{t}\right)\left(1+R_{t-1}\right)-1<50 \%$. That is, any return that is above $300 \%$ and reversed within a month is treated as missing. Secondly, we treat the monthly return as missing if the previous month end closing price is below $\$ 1$. Then we aggregate the non-missing monthly returns into annual returns. Finally, consistent with the filters applied to U.S data, we exclude regulated firms from our the sample (SIC code between 4900 and 4999) and the firm-year observations with missing number of employees, number of employees less than 50 ,

\footnotetext{
${ }^{16}$ Specifically, the firm-level stock return is given by

$$
R_{t}=\frac{P R C C D_{t} / A J E X D I_{t} \times T R F D_{t}-P R C C D_{t-1} / A J E X D I_{t-1} \times T R F D_{t-1}}{P R C C D_{t-1} / A J E X D I_{t-1} \times T R F D_{t-1}}
$$

in which $P R C C D_{t}$ is the closing price at month end, $A J E X D I_{t}$ and $T R F D_{t}$ are the corresponding share and return adjustment factors.
} 
and missing labor skill data. The final international data includes a total of 56, 412 firm-year observations. $^{17}$

\subsection{Labor skill and firm characteristics}

Before we test the model's predictions, we first investigate the characteristics of a typical firm in these two industries to understand the data. We report the unconditional characteristics of a typical firm in each industry, as well as the characteristics of these firms conditional on its current hiring rate, that is, the firms' characteristics across the five hiring portfolios within each industry. We allocate firms to an high or low skill industry at the end of June of year $t$ based on the cross sectional median value of the industry-level labor skill variable (Skill) at the end of year $t-1$. Similarly, as in the theoretical analysis, we form the five hiring portfolios separately across low and high skill industries as follows. At the end of June of year $t$, we first sort the universe of common stocks into five portfolios based on the quintile of the cross-sectional distribution of the firm-level hiring rate at the end of year $t-1$ separately across low and high skill industries. We then compute the average characteristic of each firm in each portfolio as the time-series average of the cross sectional median characteristic across all the firms in each portfolio.

\section{[Insert Table 4 here]}

The top panel in Table 4 reports the time series average of median portfolio-level characteristics of a typical firm in the two labor skill portfolios. This table shows that firms in high skill industries tend to be slightly younger, have higher hiring and investment growth rates, have higher sales, and have slightly lower book-to-market (BM) ratios (a characteristic of a growth firms) than firm in low skill industries. ${ }^{18}$ Finally, we note that firms in high skill industries have significantly higher $R \& D$ expenditures, which is expected because $R \& D$ activities typically require high skilled workers. Taken together, and consistent with the ranking of the industries reported in Table 3, these characteristics suggest that firms in high skill industries are more associated with the new economy/high tech sector (R\&D intensive, growth like firms), and the firms in the low skill industries are more associated with the old

\footnotetext{
${ }^{17}$ Due to data availability, the number of firm-year observations $(\mathrm{N})$ and the sample period varies across countries as follows. France: $N=4,888,1992-2011$; Germany: $N=5,275$, 1992-2011; Italy: N= 1,356, 1992-2011; UK: N=10, 758, 1992-2011; Canada: N=6,774, 1992-2011; Japan: N= 27, 361, 2001-2011.

${ }^{18}$ In untabulated results we also find that the difference in the average returns of the firms' in the two industries is relatively small, at least for the two sector decomposition investigated here. The average returns in the high skill industry is between $1.5 \%$ per annum and $2.5 \%$ per annum higher than in the low skill industry, and this difference is not statistically significant in our sample. This result supports our approach to examine the conditional HN spread within industries as opposed to investigating the unconditional labor skill spread.
} 
economy. In the online appendix we show that our labor skill measure has a low correlation

with other measures of labor market characteristics such as labor mobility (Donangelo, 2014) and labor unionization rates (Chen, Kacperczyk, and Ortiz-Molina, 2011)

Turning to the analysis of the characteristics of the firms across the hiring portfolios, we note that the pattern of the characteristics across the portfolios is overall similar in the two industries. Firms with currently high hiring rates tend to be younger, invest more in physical capital, have higher sales growth, and have lower book-to-market ratios (growth firms) than firms with currently low hiring rates. In addition, the firms with currently high hiring rates tend to be larger (higher market capitalization) and have lower capital-to-labor ratios, but these characteristics do not vary monotonically across the portfolios. Finally, in the high skill industry, firms with currently high hiring rate tend to invest more in R\&D as well. In the low skill industry, the pattern of R\&D expenditures across the hiring portfolios is reversed, but the R\&D intensity is very small across all firms in these portfolios.

\section{Main findings}

We follow two complementary empirical methodologies to examine the model's main asset pricing predictions. In the first approach, we run standard firm-level regressions of stock returns on the lagged firms' hiring rate. The advantage of this approach is that the estimated slopes are easy to interpret: the slope coefficient from this regression captures the link between hiring and expected stock returns (prediction P1). In addition, this approach allows us to control for firm-, year- and (in international data) country-fixed effects, thus allowing us to control for other sources of firm heterogeneity that are beyond the scope of the analysis in the model. It also allows to control for the effect of other accounting variables in an easy manner. In the second approach, we construct portfolios sorted on the firm's hiring rate and look at the properties of the ex post stock returns of the portfolios to test the model's predictions P1-P3 (see, for example, Fama and French (2008) for a discussion about the advantages and disadvantages of each approach). The two approaches allow us to crosscheck the results and establish the robustness of the findings.

\subsection{Firm-level analysis}

To test P1, we run a standard pooled OLS firm-level stock return predictability regression using the lagged firm-level hiring rate as the return predictor, and potentially other control 
variables. Specifically, we run a regression of the form:

$$
r_{i t}^{e}=a_{i}+b_{t}+c \times \mathrm{HN}_{i t-1}+d \times \mathrm{HN}_{i t-1} \times \mathrm{HSkill}_{i t-1}+e \times \mathrm{HSkill}_{i t-1}+\operatorname{controls}_{i t-1}+e_{i t},
$$

in which $r_{i t}^{e}$ in the firm $i$ annual log stock gross return from July of year $t$ to June of year $t+1, a_{i}$ is firm $i$ fixed-effect, $b_{t}$ is a year fixed-effect, $\mathrm{HN}_{i t-1}$ is the lagged value of firm $i$ hiring rate, HSkill ${ }_{i t-1}$ is a dummy variable which is one if the firm $i$ belongs to a high skill industry at the end of fiscal year end $t-2$, and controls $s_{i t-1}$ are other lagged firm-level control variables. As control variables we include the lagged value of firm $i$ investment rate, as well as the firm size (market equity), book-to-market ratio (BM) and leverage ratio. Although the inclusion of these variables is outside the scope of the theoretical analysis, we include these variables here because, from an empirical point of view, it is interesting to examine the additional explanatory power of hiring for future returns in the presence of other well established predictors. Standard errors are clustered by firm. We report the results with and without firm fixed-effects (we always include the time fixed-effect because the model predictions are for the cross section). ${ }^{19}$ Finally, it is well known that firm-level regressions can be heavily influenced by the behavior of very small firms because these firms are plentiful and have more volatile returns and characteristics (Fama and French, 2008). To make sure that our results are not mainly driven by the behavior of these small firms, we also present results where we include a dummy variable Micro $_{t}$, which is one if the firm is classified as a micro cap firm (market equity below the 20th percentile of the cross sectional distribution of market equity at time $t$ ) and also interact this variable with the firm's hiring rate and hiring rate interacted with HSkill.

\section{[Insert Table 5 Here]}

Table 5 reports the regression results across different specifications of equation (15). The regression's main coefficient of interest is coefficient $d$, which is reported in row 2. According to the theoretical analysis, this slope coefficient should be negative if the negative hiringexpected return relation is steeper in high skill industries. Overall, the table shows that the negative slope on the hiring rate variable is higher in high skill industries: the slope coefficient $d$ is estimated to be negative, and statistically significant, across all specifications.

The difference in the hiring rate slope coefficient in high and low skill industries is also economically large. We focus first on the results reported in columns 1 to 4 which do not include any additional control variables (except the micro cap dummy), and hence are more

\footnotetext{
${ }^{19}$ Note that when we include firm-fixed effects we do not include the HSkill dummy variable separately because of multicolinearity. Most firms do not switch between high and low skill industry during the whole sample period.
} 
aligned with the predictions from the model. In column 1, the slope coefficient on the interaction of hiring and the high skill dummy is -8.2 , whereas the slope coefficient on the hiring rate variable alone is -11.5. This difference is large in economic terms: a $20 \%$ increase in the firm's hiring rate (which roughly corresponds to a $20 \%$ increase in the size of the firm's workforce), is associated with a decrease of $-2.3 \%$ in firms' expected stock return in the low skill industry, and with a decrease of $-3.9 \%$ in firm's expected stock return in the high skill industry. That is, the hiring-expected return negative relation is 1.7 times steeper in high skill industries than in low skill industries. This difference in the slope coefficients increases even more when we include firm-fixed effects in column 2, and hence we control for other nonspecified forms of firm-heterogeneity in the two industries. Here, the negative hiring-expected return relation is 2.6 times steeper in high skill industries than in low skill industries. When we control for the impact of micro cap firms, the effects remain large. In

columns 3 (no firm fixed-effect) and 4 (with firm fixed-effects), the negative hiring-expected return relation is 2.3 and 2.2 times steeper in high skill industries than in low skill industries, respectively.

When we add the control variables in columns 5 to 9 , the previous qualitative analysis does not change. The slope coefficient on the interaction of hiring and high skill remains negative and statistically significant. Translating into economic magnitudes, the negative hiring-expected return relation is between 2 and 3.2 times steeper in high skill industries than in low skill industries when we control for the firms' investment rate (columns 5 to 8). In column 9, when we control for many other accounting variables, the hiring-expected returns relation is only negative in high skill industries.

Overall, the evidence reported in Table 5 supports the main theoretical prediction P1 from the model. Taken together, the hiring rate negative slope coefficient in high labor skill industries is, averaging the ratio across specifications in columns 1 to 8 , about 2.3 times larger than the slope coefficient in low labor skill industries.

\subsection{Portfolio-level analysis}

We now investigate the negative hiring-expected return relation (P1) among industries with different levels of labor skill using a portfolio approach. Consistent with the theoretical analysis, we form five one-way-sorted on hiring portfolios and compute the post-formation average excess stock returns (in excess of the risk-free rate) of the portfolios. As noted in the theory section, these portfolios are rebalanced every year at the end of June $t$, based on the quintile of the cross-sectional distribution of the firm-level hiring rate at the end of year $t-1$, and separately across low and high skill industries. Once the portfolios are formed, 
their returns are tracked from July of year $t$ to June of year $t+1$ with no rebalancing over the year. The procedure is repeated in June of year $t+1$. That is, we consider a one year buy-and-hold investment strategy because of its low transaction costs. We then also compute the Sharpe ratios and the CAPM alphas (abnormal returns) of the portfolios to check the model's predictions P2 and P3.

In computing the portfolio-level stock return, we focus on value-weighted returns to minimize the effect of the very small firms on the results. Value-weighted returns do not necessarily represent the returns of a well diversified portfolio, however, because of the heavy tails of the size distribution in the U.S. stock market. As discussed in Fama and French (2008), and Malevergne, Santa-Clara, and Sornette (2011), the characteristics of value-weighted portfolio returns are dominated by a small, albeit important, number of very large (mega cap) firms. Thus, to provide a balanced analysis of the link between hiring and stock returns in the overall economy, we impose a cap of $5 \%$ on the maximum weight of each firm in the portfolio at the time of portfolio formation and then compute the capped value-weighted portfolio returns (the firm's weight in the portfolio may exceed $5 \%$ over the course of the year if the firm has a good stock market performance because the portfolio is only rebalanced once a year to minimize turnover costs; it's a one-year buy-and-hold strategy). This constraint guarantees that the minimum effective (equal-sized) number of firms in each portfolio is twenty. In a robustness section below, we report the results using several alternative return weighting schemes to investigate the sensitivity of the results to the weighting procedure.

\section{[Insert Table 6 Here]}

The results reported in Table 6 are overall consistent with the results from the firm-level panel regressions. Table 6 reports the average excess stock returns $\left(r^{\mathrm{e}}\right)$, Sharpe ratios (SR), and CAPM alphas $(\alpha)$ of the five one-way-sorted on hiring portfolios in the low skill (left columns) and the high skill (right columns) industries. Consistent with the empirical findings in BLB, the average excess returns of the portfolio of firms with currently low hiring rates are higher than the average excess returns of the portfolio of firms with currently high hiring rates - that is, the hiring return spread is positive.

The new empirical finding is that the hiring return spread is substantially higher in the high skill industry. In particular, the hiring return spread is $2.7 \%$ per annum in the low skill labor industries, and this value is only 1.1 standard errors from zero. In high skill industries, the hiring return spread is $8.6 \%$ per annum, and this value is more than 2.7 standard errors from zero. So, the hiring return spread is 3.2 times larger in high skill industries than in low skill industries. The difference in absolute terms of the hiring return spread in the low 
and high skill industries is economically large, about 5.9\% per annum, and this value is 1.8 standard errors from zero. The Sharpe ratio of the hiring spread portfolio is about two times larger in the high skill industry than in the low skill industry. Taken together, the portfolio level evidence suggests that the negative hiring- expected return and Sharpe ratio relation is steeper for firms in high skill industries than in low skill industries, consistent with predictions P1 and P2 from the model.

We now investigate the unconditional CAPM alphas of the hiring portfolios in the two industries. According to the model's prediction P3 discussed in Section 3.2, the hiring return spread is not driven by exposure to the market factor, hence the CAPM should not be able to explain the pattern in the returns of the hiring portfolios, especially in the high skill industry in which the hiring return spread is larger. To test the CAPM, we run monthly time-series regressions of the excess returns of each portfolio on a constant and the excess returns of the market portfolio (market). The intercepts from this regression are the alphas (abnormal returns).

The results reported in Table 6 show that the CAPM cannot explain the pattern of the returns of the hiring portfolios in the high skill industry. The CAPM performs reasonably well in the low labor skill sector in which none of the portfolio level individual alphas are significant. In the high labor skill sector the CAPM generates large abnormal returns. In particular, the abnormal return of the low minus high hiring portfolio is economically large, $10.4 \%$ per annum, which is more than 3.1 standard errors from zero, and is even larger than the hiring return spread itself $(8.6 \%)$. Consistent with the predictions from the theoretical model, the alpha of the hiring return spread portfolio in the high skill industry is $8.1 \%$ larger than the hiring return spread in the low labor skill industry, and this difference is more than 2.5 standard errors from zero.

Even though the CAPM is unable to explain the cross sectional variation in the average returns of the hiring portfolios in high skill industries, the fact that the model generates a large hiring spread is consistent with the hypothesis that the hiring spread is driven by exposure to risk factors. Indeed, in the online appendix, we find that recent multifactor asset pricing models such as Hou, Xue and Zhang (2014) and Fama and French (2014) capture the hiring return spread even in the high skill industry, consistent with the hypothesis that the hiring return spread is driven by differences in risk across the hiring portfolios. Although a detailed analysis of this result is outside the scope of our analysis, this result follows because the additional factors capture the effect of the aggregate adjustment cost shock that drives the hiring return spread. 


\section{Robustness analysis}

To help establish the robustness of the main empirical findings, we now report the results from the following additional analysis: (i) use a different econometric methodology, Fama and MacBeth (1973) cross sectional regressions, to confirm the significance of the effects; (ii) examine the results in a longer sample that starts in 1963; (iii) use international data for the G7 countries to test if the model's main prediction holds in other countries as well; and (iv) investigate the sensitivity of the portfolio returns to the return weighting procedure.

\subsection{Cross sectional regressions}

The main empirical analysis reported in Section 5 is based on the results from panel OLS firm-level regressions. As discussed in, for example, Petersen (2009), the computation of the standard errors in panel data can be difficult due to the fact that, in most datasets used in empirical finance (such as the CRSP/Compustat data used here), the residuals from the panel OLS regressions are correlated across firms and time, and the exact structure of the correlation can be complex. As a result, different procedures to compute the standard errors may lead to different inferences, and it's not always clear what the appropriate method is in a given application. To partially address this concern, we consider here an alternative, albeit related, estimation method. We estimate the firm level regressions using standard cross-sectional Fama and MacBeth (1973) regressions. Specifically, in each month $t$, we run cross sectional regressions of the form:

$$
r_{i t}^{e}=\mathrm{Int}_{t}+a_{t} \times \mathrm{HN}_{i t-1}+b_{t} \times \mathrm{Micro}_{i t-1}+c_{t} \times \mathrm{HN}_{i t-1} \times \operatorname{Micro}_{i t-1}+\operatorname{controls}_{i t-1}+e_{i t},
$$

in which $r_{i t}^{e}$ is the firm $i \log$ stock return in month $t, \mathrm{Int}_{i}$ is a regression intercept, $\mathrm{HN}_{i t-1}$ is the lagged value of firm $i$ hiring rate, Micro $_{i t-1}$ is a dummy variable which is one if the firm is classified as a micro cap firm, and controls $\mathrm{s}_{i t-1}$ are other lagged firm-level control variables (we use the same control variables included in the analysis reported in Section 5). We estimate equation (16) separately across high skill and low skill industries.

[Insert Table 7 here]

Table 7 reports the estimated average slope coefficients of equation (16) in the low (L) and high $(\mathrm{H})$ skill industries. The coefficient of interest in this regression is (the average of) coefficient $b_{t}$, which is reported in row 1 . In particular, we want to test if this slope coefficient is higher (in absolute value) in high skill than in low skill industries (P1). To perform this test, we use a simple difference in means test of the estimated slope coefficient. 
The results reported in Table 7 confirm the results from the panel regressions. The estimated hiring rate slope coefficient is small (close to zero) in the low skill industry, but its large and strongly negative in the high skill industry. The difference in hiring slope coefficient in the two industries is large and statistically significant across the five different specifications considered here.

\subsection{Evidence from a long sample}

Due to the availability of the labor skill data, the main empirical analysis is based on a sample that starts in July of 1991. This restriction is necessary to make the stock return predictability analysis to be based on publicly available information (labor skill data), and hence to reflect the returns of tradable investment strategies. From an empirical point of view, however, it is natural to ask if the link between hiring and future returns is specific to the (relatively short) sample period under analysis, or if it also holds over a longer sample. To address this question, we build on the fact that our industry level labor skill measure has a very high persistence (based on the labor skill portfolio's transition probabilities, in any given year, a firm in a high skill industry has a $98 \%$ probability of being in a high skill industry in the following year), to extend the sample backwards. In particular, for each three-digit SIC industry we assign the average industry level labor skill measure between 1991 and 2001 to all the years between 1963 and 1991, a typical sample period used in empirical finance. ${ }^{20}$ We then re-do the main empirical analysis over this longer sample. We note, however, that the results from this analysis introduce additional measurement error in the analysis because the imputed 1963 to 1991 labor skill data naturally misses any technological change across industries that are associated with significant changes in the relative use of high and low skilled workers in each industry during this pre-1991 period. As such, the analysis reported here is likely to be subject to an attenuation bias.

\section{[Insert Table 8 here]}

Table 8 replicates the panel OLS regression analysis reported Section 5 using the longer sample from 1963 to 2012. Again, the coefficient of interest is the coefficient associated with the firm-level lagged hiring rate interacted with the high skill dummy, which is reported in row 2. Across all specifications, this slope coefficient is always negative and statistically significant. As such, the finding that the negative hiring-expected return relation is steeper in industries with more skilled labor does not seem to be specific to the shorter sample.

\footnotetext{
${ }^{20}$ We start in 1963 because before this date the number of firms which report the number of employees data necessary to construct the firm-level hiring rate is small.
} 
The economic magnitude of the difference in the hiring rate slope coefficient across industries remains large, although they are, as expected, slightly smaller than those reported in the shorter sample due to attenuation bias. When no control variables are included, columns 1 (no firm fixed-effects) and 2 (with firm fixed-effects), the negative hiring-expected return relation is 1.5 and 1.8 times steeper in high skill industries than in low skill industries, respectively. When we control for the effect of micro cap firms in columns 3 (no firm fixedeffect) and 4 (with firm fixed-effects), the negative hiring-expected return relation is 1.9 and 2 times steeper in high skill industries than in low skill industries, respectively. When we add the control variables in columns 5 to 9 , the qualitative analysis does not change.

\subsection{Evidence from international data}

The main empirical analysis is based on U.S. data. Here, we examine if the results also hold in international data. We focus on data for developed countries, in particular, the G7 countries. We exclude the U.S. from this sample because the results for the U.S. were examined in the previous sections. Naturally, the magnitude of the labor adjustment costs varies across these countries because of, for example, differences in labor legislations and local labor market conditions. But the relative size of the labor adjustment costs is likely to be higher in high skill industries than in low skill industry in these countries as well. ${ }^{21}$ As a result, the international data provides an interesting sample to further test the model's predictions. In this section, we focus on prediction P1.

In the absence of country-specific labor skill data, we assign to each country in our sample the same low and high skill industry classification used in the U.S. sample. It is unlikely that this procedure introduces any significant biases in the analysis because the classification is based on primitive features of the technology, and it is natural to expect the primitive features of the technology to be similar across countries. We then replicate the analysis reported in Section 5 using the international data. In particular, we estimate a pooled OLS firm-level stock return predictability regression similar to regression equation 15, and we allow the year fixed-effects to vary across countries. Due to data availability, we only use the lagged value of firm $i$ investment rate, and the micro dummy, as the control variables. The micro dummy variable is defined at the country level. Specifically, in each year $t$, a firm $i$ is classified as a micro cap if the market equity of the firm in year $t-1$ is below the 20th percentile of the cross sectional distribution of market equity in firm's $i$ country.

[Insert Table 9 here]

\footnotetext{
${ }^{21}$ The empirical evidence on the relative size of labor adjustment costs of high and low skilled workers discussed in the related literature section covers studies based on data for both the U.S. and other countries.
} 
Table 9 reports the slope coefficients of equation (15) estimated in the international data. The slope coefficient of interest in this regression is reported in row 2. As before, this coefficient should be negative if the negative hiring-expected return relation is steeper in industries with more skilled workers. The results from the international data seem to provide additional support for this prediction. When no control variables are included (columns 1 and 2), the hiring-expected return negative relation is 2.3 and 1.7 times steeper in high skill industries than in low skill industries, respectively. When we control for the effect of micro cap firms, the effects remain large. In columns 3 (no firm fixed-effect) and 4 (with firm fixed-effects), the hiring-expected return negative relation is 2 and 1.6 times steeper in high skill industries than in low skill industries, respectively. When we add the control variables in columns 5 to 8, the qualitative analysis does not change. Taken together, the results from the international data are consistent with the analysis for the U.S.. Similar to the analysis of the results in the longer sample, however, we note that the magnitude of the difference in the hiring rate slopes across industries is marginally smaller in the international data than in the U.S. data.

\subsection{Alternative portfolio-level analysis}

In the benchmark portfolios-analysis reported in Section 5.2, we compute the average returns of the hiring portfolios in the low and high skill industries as average value-weighted returns, in which the maximum weight of each firm in each portfolio is constrained to be at most $5 \%$ at the time of portfolio formation. In this section we consider four alternative return weighting procedures. To be conservative, we continue to focus on one-year buy-and-hold investment strategies (allowing monthly portfolio rebalancing to keep the weight of each firm constant over the year produces stronger results than those reported here).

In the first procedure, which we refer to as equal-weighted, we compute the returns of a portfolio assigning the same weight to all firms at the time portfolio formation (the weights vary over the year due to the changes in the firm's relative market values). The second procedure is equal to the previous equal-weighting procedure but we exclude the micro cap firms from the portfolios, to avoid the large influence of these firms in the portfolio average returns. In the third procedure we weight each firm by the firms' lagged labor force at the time of portfolio formation, and we refer to these portfolios as number of employeesweighted. Finally, in the last procedure, we weight each firm by the standard one month lagged market value of equity of each firm, which corresponds to the standard value-weighting procedure. The last two procedures allow us to investigate if the differences in the negative hiring-expected return relationship across industries also varies with firm size in a systematic 
manner.

[Insert Table 10 here]

The results from average equal-weighted returns (with and without micro caps), are consistent with the results reported for the baseline capped value-weighted portfolios. When all firms are included, the hiring return spread in the high skill industry is $10.1 \%$ per annum, which is more than 4.2 standard errors from zero, and its only $3.2 \%$ per annum in the low skill industry, which is only 1.2 standard errors from zero. The difference in the hiring return spread in the two industries is $6.9 \%$ per annum, which is more than 2.5 standard errors from zero. This means that the hiring return spread is three times larger in the high skill industry than in the low skill industry. The pattern of the Sharpe ratio and CAPM alpha of the hiring spread portfolio are qualitatively similar to the analysis of the pattern of average returns. The conclusions are similar when the micro cap firms are excluded from the portfolios (All but micro equal-weighted).

Turning to the analysis of the portfolio returns weighted by measures related to firm size, Table 10 shows that when the returns are weighted by the firm's lagged number of employees, the hiring return spread in the high skill industry is $9.6 \%$ per annum, which is more than 3.6 standard errors from zero, and it's only $2.2 \%$ per annum in the low skill industry, and this value is not statistically significant. Thus, when the average returns are weighted by the number of employees, the hiring return spread is 4.3 times larger in the high skill industry than in the low skill industry. Similarly, the CAPM alpha of the hiring spread portfolio is $8.6 \%$ larger in the high skill industry than in the low skill industry, and this difference is more than 2.1 standard errors from zero. Thus, the difference in the average returns and CAPM alpha of the hiring spread portfolio in low and high skill industries is substantially larger here than in the baseline procedure with capped value-weighted average results. A similar result holds for the pattern of the Sharpe ratios of the hiring spread portfolio across the two industries. The stronger result with this return weighting procedure is expected because the hiring/firing frictions should naturally be more important among more labor intensive firms, which is captured here by weighting the average returns by the size of each firms' labor force.

Finally, turning to the analysis of the portfolio returns weighted by market equity (which corresponds to standard value-weighted returns), we see that the difference in the hiring return spread in low skill and high skill industries is significantly smaller than in the baseline set of results. In the high skill industry, the hiring return spread is $5.9 \%$ per annum, which is more than 1.9 standard errors from zero. In the low skill industry, the hiring return spread is $4.6 \%$ per annum, but is not statistically significant. Thus, when the average returns 
are weighted by the firm's market capitalization, the hiring return spread is only 1.3 times larger in the high skill industry than in the low skill industry. When we look at the difference in the CAPM alphas of the hiring spread portfolio in the low and high skill industry the difference in the CAPM alpha of the hiring spread portfolio remains economically large, about $3.8 \%$ per annum, but it's not statistically significant. The Sharpe ratio of the hiring spread portfolio remains larger in the high skill industry than in the low skill industry, but the difference in Sharpe ratio is now only 0.1 (the Sharpe ratio of the HN spread portfolio is 1.3 times larger in the high skill industry relative to the low skill industry). Although it is tempting to interpret these smaller differences in the hiring return/Sharpe ratio/CAPM alpha spreads across low and high skill industries as evidence that the support for the model's predictions are weaker for large firms, the stronger results using employee-weighted returns speak against this interpretation. Taken together, the differences in the hiring return/CAPM alpha/Sharpe ratios spreads between low skill and high skill industries are large among large firms, provided that the size measure is directly related to the size of the firm's labor force. This result is intuitive because weighting by the size of the firm's labor force (instead of market equity) captures more directly the importance of the labor adjustment cost friction for a firm (for example, the labor frictions are likely to be less important for very large firm that are more physical capital intensive).

\section{Other dimensions of labor heterogeneity}

So far we have investigated the implications of differences in the size of labor adjustment costs of high skilled and low skilled workers for asset prices. Naturally, high skilled and low skilled workers differ in many other dimensions as well. Here, we incorporate realistic features of labor-force heterogeneity in the model by considering alternative calibrations, and investigate its impact on the model predictions for asset prices in high and low skill industries. In addition, we examine the implications of the model for real quantities, in particular, for the properties of firm's endogenous hiring and investment rates.

Incorporating other sources of heterogeneity in the model seems important here because, as reported in Table 2, column 2, row 7 , the baseline model fails to capture the relative properties of sales, hiring and investment rates in the two industries. In the baseline model, the volatility of sales (measured in the model as total output) is counterfactually lower in the high skill industry than in the low skill industry. Related, rows 10 and 11 show that the baseline model predicts that the volatility of hiring and investment rates are counterfactually lower in the high skill industry than in the low skill industry. These results follow because, in the baseline calibration, the firms in the low skill industry face lower costs of adjusting 
labor, thus having a more volatile labor force, which in turn leads to a more volatile output and volatile hiring rate. Due to the complementarity between labor and capital, the physical capital investment rate also inherits this higher volatility.

In what follows, we focus on the following two additional features of labor-force heterogeneity which are consistent with the empirical evidence reported in previous studies (discussed in the related literature section), and with additional evidence that we provide here: (i) differences in the economic environment (demand/TFP volatility) of the industries in which high skilled and low skilled workers operate; and (ii) differences in the productivity and the wage rate process of high skill and low skilled workers.

As we show here, while adding these additional features allows us to improve the model fit on several dimensions (especially for real quantities), these features do not affect in a quantitatively important way the key testable predictions relating firm's hiring decisions and asset prices across industries with different levels of labor skills that we obtain from the baseline model with only differences in the labor adjustment cost parameter. In this sense, the testable predictions from the model that we take to the data (P1 to P3) are robust predictions.

\subsection{Heterogeneity in the economic environment}

The volatility of key real variables in the low and high skill industry suggests that the economic environment in which the two industries operate is different. As reported in Table 2, column 5 (Data), row 7 shows that the relative standard deviation of the firm-level real sales growth is about $24 \%$ higher in the high skill industry than in the low skill industry (in levels, the standard deviation of real sales growth is $38 \%$ versus $31 \%$ per annum, respectively; a qualitatively similar result is obtained if we look at the volatility of profits- not tabulated). The higher volatility of sales in the high skill industry suggests that the firms in this industry are subject to more volatile demand and/or productivity shocks. Here, we incorporate this additional source of heterogeneity in the model and examine its impact on the model's key asset pricing predictions (P1-P3), and on the moments for real quantities. Ignoring this feature of the data might lead to a wrong assessment of the model's fit.

We incorporate heterogeneity in the economic environment in the two industries by specifying the volatility of the firm-specific productivity shocks in the two industries to be different, that is, we calibrate $\sigma_{z \text {,high }}>\sigma_{z \text {,low }}$. Specifically, we calibrate these two parameters to roughly match the relative volatility of the endogenous hiring rates in the two industries (which is close to 1 ), and set $\sigma_{z \text {,high }}=0.14$ and $\sigma_{z \text {,low }}=0.08$ (recall that in the baseline calibration we set $\left.\sigma_{z}=0.10\right)$. We maintain the difference in the labor adjustment costs 
parameters to be equal to the baseline calibration so that we can evaluate the incremental impact of this source of heterogeneity on the model's fit.

As reported in Table 2, column 3, rows 7 and 10, by construction, this extended model fits significantly better the relative volatilities of the firm-level sales growth and hiring rates observed in the data. Row 11 also shows that this extended model also fits better the properties of the firm-level investment rate in the two industries, in particular, it captures the fact that the standard deviation of the firm-level investment rate is higher in the high skill industry than in the low skill industry (the ratio is 1.33 in the data; but its 0.96 in the baseline model and 1.19 here). More important, the key asset pricing implications predictions of the model relating the hiring rate and stock returns do not change in any quantitatively meaningful way. Column 3, rows 1 to 6 show that the key testable predictions P1 to P3 remain valid in this more realistic calibration of the model as well, in particular, the hiring return and CAPM alpha spread, and the Sharpe ratio of the hiring spread portfolio is only large in the high skill industry, and the model implied moments are very close to those obtained in the baseline model. Taken together, we conclude that difference in the volatility of idiosyncratic volatility shocks in the two industries helps improve the model's for real quantities, but this source of heterogeneity has a small impact on the model's key predictions for asset prices obtained from the baseline model.

\subsection{Heterogeneity in wages}

By definition, high skilled workers are more productive than low skilled workers (that is $\left.\lambda_{\text {high }}>\lambda_{\text {low }}\right)$, and thus receive higher wages in equilibrium $\left(\mathrm{W}_{t, \text { high }}>\mathrm{W}_{t, \text { low }}\right)$. At the same time, the volatility of the real wage rate is smaller for high skilled workers than for low skilled workers. As reported in Table 2, column 5 (Data), row 8, the average real wage in a high skill industry is about $38 \%$ higher than in a low skill industry. ${ }^{22}$ Row 9 shows that the standard deviation of wage growth in the high skill industry is only $62 \%$ of the standard deviation of real wage growth in the low skill industry (the annual wage growth standard deviations are $2.3 \%$ and $1.4 \%$, respectively). As discussed in the related literature section, the higher rigidity of wages of high skilled workers relative to low skilled workers is a well documented fact in the labor economics literature.

\footnotetext{
${ }^{22}$ Note that this ratio is for the average wage in each industry, not for the ratio of the wages of a high skill vs. low skilled worker. Because both industries employee both low skill and high skilled workers (but in different proportions), the average represents an intermediate value of the ratio of the two wages. If we take the average fraction of high skilled workers to be 0.32 in the high skill industry and 0.10 in the low skill industry (as reported in Table 4), and solve for the effective ratio of the wage rate of a high skilled worker relative to low skilled worker, the estimated ratio is 3.03, that is, a typical high skilled worker has an annual wage rate three times larger than a low skilled worker.
} 
To incorporate the previous differences in the model, we consider an alternative calibration of the model in which we set the relative productivity of a typical worker in the high skill industry to be $\lambda_{\text {high }}=1.38$, and in the low skill industry to be $\lambda_{\text {low }}=1$, which is the value used in the baseline calibration. We set the parameters of the wage rate process in the two industries to roughly match the relative mean and standard deviation of the wage rate in the two industries. This leads to the following parameters: $\tau_{1, \text { high }}=0.0095$, $\tau_{1, \text { low }}=0.0032, \tau_{2 \text {,high }}=0.98$, and $\tau_{2 \text {, low }}=0.75$. We maintain the difference in the labor adjustment costs parameters and idiosyncratic productivity to be equal to the parameters used in the previous section (calibration results reported in Table 2, column 3), so that we can continue to evaluate the incremental impact of this additional source of heterogeneity.

As reported in Table 2, column 4, rows 7 to 11, this extended model is now overall consistent with the relative properties of the hiring rate, investment, and wages in the two industries. More important, and consistent with the analysis in the previous section, the fit of the model for the key asset pricing implications relating the hiring rate and asset prices (hiring spread portfolio) do not change in a quantitatively meaningful way. Rows 1 to 6 show that the key testable predictions P1 to P3 remain valid in this more realistic calibration of the model as well, and the model implied moments are very close to those obtained in the baseline model. This result is intuitive. The rigidity of the wage rate operates in the model through an operating leverage effect: with less flexible costs, the volatility of the firm's profits (and hence of the payments to shareholders) increases. But, as discussed in the theory Section 3.2, the hiring return spread in the baseline calibration of the model is not driven by an operating leverage effect; it is mostly driven by exposure to the aggregate adjustment cost shock, and is due to labor adjustment costs. As such, it is natural to expect that the change in the properties of the wage rate processes across industries has a relatively minor impact on the properties of the hiring return spread in the model, at least within the set of realistic parameter values of the wage rate processes considered in this and the baseline's calibrations.

\section{Conclusion}

We show novel empirical linkages between the stock market and the labor market. We find that the negative hiring-expected return relation identified in previous studies is steeper in high skill industries than in low skill industries. This result holds in data for the U.S. and in international data for the G7 countries. Theoretically, we introduce labor-force heterogeneity in a standard model of investment to show that this result supports the hypothesis that labor adjustment costs are higher for more skilled workers than for low skilled workers, a 
hypothesis that is also consistent with empirical evidence from the labor demand literature. In addition, we show that the Sharpe ratios of the hiring rate spread portfolio varies with the composition of the industry labor force. In particular, the Sharpe ratio of the hiring rate spread portfolio is substantially larger in high labor skill industries than in low labor skill industries. Finally, we show that the steeper negative expected return-hiring relation in industries with higher labor skills is not explained by exposure to the aggregate market factor, that is, the unconditional CAPM cannot explain the returns of these portfolios, consistent with the theoretical analysis.

Taken together, our results show that labor-force heterogeneity affects asset prices in financial markets. This result has broader implications for the link between the asset pricing and labor economics literatures. Our findings suggest that financial market variables, which are typically ignored in the labor economics literature, can be a useful source of information about the importance of labor market frictions. At the same time, our results suggest that the characteristics of the labor force, which are typically ignored in the asset pricing literature, is an important determinant of equilibrium risk premiums in the cross section.

Relaxing some of our simplifying assumptions would lead to interesting extensions of the model and to novel empirical predictions. Here, we take the wage rate process to be exogenous. In a general equilibrium setting in which wage rates are determined through, for example, Nash bergaining, the difference in bargaining power of high and low skilled workers is likely to further affect the properties of firm's cash flows, and hence potentially generate additional differences in risk premiums in the cross section. In addition, a large literature on capital-skill complementarity suggests that elasticity of substitution between capital and unskilled labor is higher than that between capital and skilled labor. ${ }^{23}$ In turn, this difference is likely to affect the firms' ability to respond to aggregate shocks, and hence generate additional cross sectional variation in equilibrium risk premiums. Finally, our analyses ignore worker's training, which can have implications for the endogenous size of labor adjustment costs. Firms can adjust their skilled labor force not only by hiring skilled workers but also by training unskilled workers internally, and hence avoid part of the large hiring costs associated with hiring high skilled workers in the future. Examining the impact of these and other labor related differences on asset prices is an interesting topic for future research.

\footnotetext{
${ }^{23}$ See, for example, Griliches (1969), and more recently, Greenwood, Hercowitz, and Krussel (1997), Krussel, Ohanian, Rios-Rull, and Violante (2000), and Duffy, Papageorgiou, and Perez-Sebastian (2004).
} 


\section{References}

[1] Acemoglu, Daron, 2001, Good jobs versus bad jobs, Journal of Labor Economics, 19(1), $1-21$

[2] Andrew B. Abel, and Olivier J. Blanchard ,1986, The present value of profits and the cyclical variability of investment, Econometrica, 54(2), $249-273$

[3] Asness, Clifford, R. Burt Porter, and Ross Stevens, 2000, Predicting stock returns using industry-relative firm characteristics, Working paper, Iowa State University

[4] Belo, Frederico, Xiaoji Lin, and Santiago Bazdresch, 2014, Labor hiring, investment, and stock return predictability in the cross section, Journal of Political Economy, 122(1), 129-177

[5] Berk, Jonathan B., Richard C. Green, and Vasant Naik, 1999, Optimal investment, growth options and security returns, Journal of Finance 54, 1153-1607.

[6] Berk, J., and J. Walden, 2013, Limited capital market participation and human capital risk, Review of Asset Pricing Studies, 3(1), 1 - 37

[7] Betermier, Sebastien, Thomas Jansson, Christine Parlour, and Johan Walden, 2012, Hedging labor income risk, Journal of Financial Economics, 105(3), 622 - 639

[8] Blatter, M., S. Muehlemann, S. Schenker, and S. Wolter, 2012, Hiring costs of skilled workers and the supply of firm-provided training, working paper, University of Bern

[9] Bloom, Nicholas, 2009, The impact of uncertainty shocks, Econometrica, 77(3), $623-685$

[10] Bond, Stephen, and John Van Reenen, 2007, Microeconometric models of investment and employment, Handbook of econometrics, 6, 4417 - 4500

[11] Boyd, John H., Jian Hu, and Ravi Jagannathan, 2005, The stock market's reaction to unemployment news: Why bad news is usually good for stocks, Journal of Finance, $60(2), 649-672$

[12] Button, Peter, 1990, The cost of labour turnover: an accounting perspective, Labour Economics and Productivity 2, $146-160$

[13] Caballero, Ricardo. 2007, Specificity and the Macroeconomics of Restructuring. MIT Press 
[14] Caju, Philip Du, Catherine Fuss, and Ladislav Wintr, 2007, Downward wage rigidity for different workers and firms : an evaluation for Belgium using the IWFP procedure, Working Paper, European Central Bank.

[15] Campbell III, Carl M. ,1997, The variation in wage rigidity by occupation and union status in the US, Oxford Bulletin of Economics and Statistics, 59, 133 - 147

[16] Cappelli, Peter, and Steffanie L. Wilk, 1997, Understanding selection processes: organization determinants and performance outcomes, Mimeo, The Wharton School

[17] Chen, Huafeng Jason, Marcin Kacperczyk, and Hernn Ortiz-Molina, 2011, Labor unions, operating flexibility, and the cost of equity, Journal of Financial and Quantitative Analysis, 46, 25-58

[18] Cochrane, John, 1991, Production-based asset pricing and the link between stock returns and economic fluctuations, Journal of Finance 461, $209-237$

[19] Cochrane, John, 2005, Financial Markets and the Real Economy, Foundations and Trends(R) in Finance, 1, $1 \mathrm{C} 101$.

[20] Danthine, Jean-Pierre, and John B. Donaldson, 2002, Labour relations and asset returns, Review of Economic Studies, 69(1), 41 - 64

[21] Davis, Steven, R. Jason Faberman, and John Haltiwanger, 2006, The flow approach to labor markets: New data sources and micro-macro links, Journal of Economic Perspectives, 20(3), $3-26$

[22] Diamond, Peter A, 1982, Aggregate demand management in search equilibrium, Journal of Political Economy, 90(5), 881 - 894

[23] Dolfin, Sarah, 2006, An examination of firms' employment costs, Applied Economics, $38(8), 861-878$

[24] Donangelo, Andres, 2009, Investments in human capital and expected asset returns, Working Paper, University of Texas at Austin

[25] Donangelo, Andres, 2014, Labor mobility: implications for asset pricing, Journal of Finance, 68(3), $1321-1346$

[26] Donangelo, Andres, Francois Gourio, and Miguel Palacios, 2015, Labor leverage and the value spread, Working Paper, University of Texas at Austin 
[27] Dube, Arindrajit, Eric Freeman, and Michael Reich, 2010, Employee replacement costs, Working Paper, UC Berkeley: Institute for Research on Labor and Employment

[28] Duffy, John, Chris Papageorgiou, and Fidel Perez-Sebastian, 2004, Capital-skill complementarity? Evidence from a panel of countries, Review of Economics and Statistics, 86(1), $327-344$

[29] Eiling, Esther, 2011, Industry-specific human capital, idiosyncratic risk and the crosssection of expected stock returns, Journal of Finance, 68(1), $43-84$

[30] Eisfeldt, Andrea and Dimitris Papanikolaou, 2013, Organizational capital and the cross-section of expected returns, Journal of Finance, 68(4), 1365 - 1406

[31] Fama, Eugene F., and Kenneth R. French, 1993, Common risk factors in the returns on stocks and bonds, Journal of Financial Economics 33, 3 - 56

[32] Fama, Eugene F., and Kenneth R. French, 2008, Dissecting anomalies, Journal of Finance, 63(4), $1653-1678$

[33] Fama, Eugene F., and Kenneth R. French, 2014, A five-factor asset pricing model, Journal of Financial Economics, forthcoming

[34] Fama, Eugene F., and James D. MacBeth, 1973, Risk, return, and equilibrium: Empirical tests, Journal of Political Economy, 81(3) 607

[35] Fama, Eugene F. and G. William Schwert, 1977, Human capital and capital market equilibrium, Journal of Financial Economics, 4(1), 95-125

[36] Favilukis, Jack, and Xiaoji Lin, 2015, Wage rigidity: A solution to several asset pricing puzzles, Review of Financial Studies, forthcoming

[37] Greenwood, Jeremy, Hercowitz, Zvi, and Per Krusell,1997, Long-run implications of investment-specific technological change, American Economic Review, 87(3), 342-362

[38] Griliches, Zvi ,1969, Capital-skill complementarity, Review of Economics and Statistics, $51(4), 465-468$

[39] Hall, Robert, 2014, High discounts and high unemployment, NBER working paper 19871

[40] Hamermesh, Daniel S, 1993, Labor demand, $1^{\text {st }}$ ed, Princeton University Press 
[41] Hamermesh, Daniel S and Gerard Pfann, 1996, Adjustment costs in factor demand, Journal of Economic Literature, XXXIV, 1264 - 1292

[42] Hou, Kewei, Andrew Karolyi, and Bon-Chan Kho, 2011, What Factors Drive Global Stock Returns?, Review of Financial Studies, 24(8), 2527-2574.

[43] Hou, Kewei, Lu Zhang, and Chen Xue, 2014, Digesting anomalies: An investment approach, Review of Financial Studies, 28(3), 650-705

[44] Imrohoroglu, Ayse, and Selale Tuzel, 2014, Firm-level productivity, risk, and return, Management Science, 60, 2073-2090.

[45] Ince, Ozgur, and R. Burt Porter, 2006, Individual equity return data from Thomson Datastream: Handle with care!, Journal of Financial Research, 29(4), 463C479.

[46] Jagannathan, Ravi and Zenyu Wang, 1996, The conditional CAPM and the crosssection of expected returns, The Journal of Finance, 51, 3-53

[47] Jermann, Urban J, 1998, Asset pricing in production economies, Journal of Monetary Economics, 41(2), $257-275$

[48] Kogan, Leonid, 2001, An equilibrium model of irreversible investment, Journal of Financial Economics, 62, 201 - 245

[49] Kogan, Leonid, 2004. Asset prices and real investment, Journal of Financial Economics 73, 411-431

[50] Kogan, Leonid, and Dimitris Papanikolaou, 2012, Economic activity of firms and asset prices, Annual Review of Financial Economics, 4, 361-384

[51] Kogan, Leonid, and Dimitris Papanikolaou, 2013, Firm characteristics and stock returns: The role of investment-specific shocks, Review of Financial Studies, 26(11), $2718-2759$

[52] Kogan, Leonid, and Dimitris Papanikolaou, 2014, Growth opportunities, technology shocks and asset prices, Journal of Finance, 69(2), $675-718$

[53] Krussel, Per, Lee Ohanian, Jose-Victor Rios-Rull, Geovanni L. Violante, 2000, Capitalskill complementarity and inequality: A macroeconomic analysis, Econometrica, 68(5), $1029-1053$

[54] Kuehn, Lars-Alexander, Mikhail Simutin, and Jessie J. Wang, 2014, A labor capital asset pricing model, Working Paper 
[55] Kydland, Finn E., 1984, Labor-force heterogeneity and the business cycle, CarnegieRochester Conference Series on Public Policy, 21, 173 - 208

[56] Lagakos, David, and Guillermo Ordonez, 2011, Which workers get insurance within the firm?, Journal of Monetary Economics, 58, $632-645$

[57] Lettau, Martin, and Jessica A. Wachter, 2007, Why is long-horizon equity less risky? A duration-based explanation of the value premium, Journal of Finance 62, 55-92

[58] Li, Dongmei and Lu Zhang, 2010, Does q-theory with investment frictions explain anomalies in the cross-section of returns?, Journal of Financial Economics, 98(2), $297-314$

[59] Li, Erica X. N., Dmitry Livdan, and Lu Zhang, 2009, Anomalies, Review of Financial Studies, 22 (11), 4301-4334

[60] Liu, Laura X. L., Toni M. Whited, and Lu Zhang, 2009, Investment-based expected stock returns, Journal of Political Economy, 117(6), 1105 - 1139

[61] Lustig, Hanno, and Stijn Van Nieuwerburgh, 2008, The returns on human capital: Good news on wall street is bad news on main street, Review of Financial Studies, $21(5), 2097-2137$

[62] Lustig, Hanno, Chad Syverson, and Stijn Van Nieuwerburgh, 2011, Technological Change and the Growing Inequality in Managerial Compensation, Journal of Financial Economics, 99(3), $601-627$

[63] Malevergne, Yannick, Pedro Santa-Clara, and Didier Sornette (2011), Professor Zipf goes to Wall Street, Working Paper

[64] Mayers, David, 1972, Non-marketable assets and capital market equilibrium under uncertainty, in Jensen, M. Studies in the Theory of Capital Markets, Praeger, New York,223 - 248

[65] McGrattan, Ellen R., 1999, Application of weighted residual methods to dynamic economic models. In Computational Methods for the Study of Dynamic Economies, Chapter 6, eds. R. Marimon and A. Scott. Oxford: Oxford University Press

[66] Merz, Monika, and Eran Yashiv, 2007, Labor and the market value of the firm, American Economic Review, 97(4), 1419 - 1431 
[67] Mincer, Jacob, 1962, On-the-job training: Costs, returns, and some implications, Journal of Political Economy, 70(5), 50 - 79

[68] Mortensen, Dale T, 1982, Property rights and efficiency in mating, racing, and related games, American Economic Review, 72(5) 968 - 979

[69] Ochoa, Marcelo, 2013, Volatility, labor heterogeneity, and asset prices, Working Paper

[70] Oi, Walter Y., 1962, Labor as a quasi-fixed factor, Journal of Political Economy 70 , $538-555$

[71] Palacios, Miguel, 2015, Human capital as an asset class: Implications from a general equilibrium model, Review of Financial Studies, 28(4), 978 - 1023

[72] Palacios, Miguel, and Alex Stomper, 2014, Training the doubtful and timid, working paper, Vanderbilt University

[73] Parker, Jonathan, and Annette Vissing-Jorgensen, 2009, Who bears aggregate fluctuations and how?, American Economic Review Papers and Proceedings

[74] Parker, Jonathan, and Annette Vissing-Jorgensen, 2010, The increase in income cyclicality of high-income households and its relation to the rise in top income shares, Brookings Papers on EconomicActivity

[75] Parlour, Christine, and Johan Walden, 2011, General equilibrium returns to human and investment capital under moral hazard, Review of Economic Studies, 78(1), 394 - 428

[76] Petersen, Mitchel A., 2009, Estimating standard errors in finance panel data sets: Comparing approaches, Review of Financial Studies, 22, 435 - 480

[77] Petrosky-Nadeau, Nicolas, Lu Zhang, and Lars-Alexander Khuen, 2013, Endogenous disasters and asset prices, working paper, Carnegie Mellon University and Ohio State University

[78] Pissarides, Christopher A., 1985, Short-run equilibrium dynamics of unemployment, vacancies, and real wages, American Economic Review, 75(4), 676 - 690

[79] Rouwenhorst, K. Geert, 1995, Asset pricing implications of equilibrium business cycle models, In Frontiers of business cycle research, Ed T.F. Cooley(ed), Princeton University Press, $294-330$

[80] Santos, Tano and Pietro Veronesi, 2006, Labor Income and Predictability of Stock Returns, Review of Financial Studies, 19, 1 - 44 
[81] Shapiro, Matthew D, 1986, The dynamic demand for capital and labor, Quarterly Journal of Economics, 101(3), 513 - 542

[82] Shumway, Tyler, 1997, The delisting bias in CRSP data, 1997, Journal of Finance, 52, $327-340$

[83] Tauchen, George, and Robert Hussey, 1991, Quadrature-based methods for obtaining approximate solutions to nonlinear asset pricing models, Econometrica, 59(2), 371-396

[84] Tuzel, Selale, 2009, Corporate real estate holdings and the cross section of stock returns, Review of Financial Studies, 23(6), 2268 - 2302

[85] Uhlig, Harald, 2007, Explaining asset prices with external habits and wage rigidities in a DSGE model, American Economic Review, 97(2), 239 - 243

[86] Zhang, Lu, 2005, The value premium, The Journal of Finance, 60(1), 67 - 103 


\section{A-1 Numerical Algorithm}

All of the endogenous variables in the model are functions of the state variables. Because the functional forms are not available analytically, we solve for these functions numerically. The model is solved at a monthly frequency, which is the frequency of the stock return data used in the empirical tests. Because all the firm-level accounting variables in the data are only available at an annual frequency, we time-aggregate the simulated accounting data to make the model-implied moments comparable with those in the data. ${ }^{24}$

We use the value function iteration procedure to solve the firm's maximization problem. The value function and the optimal decision rule are solved on a grid in a discrete state space. We specify a grid of 27 points for capital and labor, respectively, with upper bounds $\bar{k}$ and $\bar{n}$ that are large enough to be nonbinding. The grids for capital and labor stocks are constructed recursively, following McGrattan (1999), that is, $k_{i}=k_{i-1}+c_{k 1} \exp \left(c_{k 2}(i-2)\right)$, where $i=1, \ldots, 27$ is the index of grids points and $c_{k 1}$ and $c_{k 2}$ are two constants chosen to provide the desired number of grid points and two upper bounds $\bar{k}$ and $\bar{n}$, given two prespecified lower bounds $\underline{\mathrm{k}}$ and $\underline{\mathrm{n}}$. The advantage of this recursive construction is that more grid points are assigned around $\underline{k}$ and $\underline{n}$, where the value function has most of its curvature.

The aggregate productivity shock $\varepsilon_{t}^{x}$ is an i.i.d. standard normal shock. We discretize $\varepsilon_{t}^{x}$ into 5 grid points using Gauss-Hermite quadrature. The state variables $s$ and $z$ have continuous support in the theoretical model, but they have to be transformed into discrete state space for the numerical implementation. The popular method of Tauchen and Hussey (1991) does not work well when the persistence level is above 0.9. Because both the aggregate adjustment cost wedge and idiosyncratic productivity processes are highly persistent, we use the method described in Rouwenhorst (1995) for a quadrature of the Gaussian shocks. We use 9 grid points for the $s$ process and 5 grid points for the $z$ process. In all cases, the results are robust to finer grids as well. Once the discrete state space is available, the conditional expectation can be carried out simply as a matrix multiplication. Cubic spline interpolation is used extensively to obtain optimal investment and hiring that do not lie directly on the grid points. Finally, we use a simple discrete global search routine in maximizing the firm's problem.

\footnotetext{
${ }^{24}$ Because firms are all-equity financed in the model, but use both debt and equity in the real data, we leverage up all returns generated in the model to make them comparable with the data. We compute the model-implied levered return as $r_{t+1}^{e}=(1+$ Debt/Equity $) \times\left(R_{t}^{a}-R_{f}\right)$, where $R^{a}$ is the return of the allequity firm in the model, $R_{f}$ is the risk-free rate, and Equity/Debt is the average equity-to-debt ratio in the data (0.67).
} 


\section{A-2 Specific vocational preparation (SVP) index}

In this appendix, we describe the Specific Vocational Preparation (SVP) index used to construct our industry-level labor skill measure in more detail. The data on SVP index comes from the Dictionary of Occupational Titles (DOT): Revised Fourth Edition, 1991 from U.S. Department of Labor. For each occupation, the SVP index is defined based on the amount of time required by a typical worker in the occupation to learn the techniques, acquire the information, and develop the facility needed for average performance in a specific job-worker situation.

This training may be acquired in a school, work, military, institutional, or vocational environment. It does not include the orientation time required of a fully qualified worker to become accustomed to the special conditions of any new job. Specific vocational training includes: vocational education, apprenticeship training, in-plant training, on-the-job training, and essential experience in other jobs.

Specific vocational training includes training given in any of the following circumstances:

a. Vocational education (high school; commercial or shop training; technical school; art school; and that part of college training which is organized around a specific vocational objective);

b. Apprenticeship training (for apprenticeable jobs only);

c. In-plant training (organized classroom study provided by an employer);

d. On-the-job training (serving as learner or trainee on the job under the instruction of a qualified worker);

e. Essential experience in other jobs (serving in less responsible jobs which lead to the higher grade job or serving in other jobs which qualify).

The following is an explanation of the various levels of specific vocational preparation:

1. Short demonstration only;

2. Anything beyond short demonstration up to and including 1 month;

3. Over 1 month up to and including 3 months;

4. Over 3 months up to and including 6 months;

5. Over 6 months up to and including 1 year;

6. Over 1 year up to and including 2 years;

7. Over 2 years up to and including 4 years;

8. Over 4 years up to and including 10 years;

9. Over 10 years 
Table 1: Baseline parameter values

This table presents the parameter values of the baseline model (BLB) with no labor-force heterogeneity.

\begin{tabular}{lcr}
\hline \hline \multicolumn{1}{c}{ Parameter } & Symbol & Value \\
\hline Technology: general & & \\
Weight of physical capital in the production function & $\alpha$ & 0.36 \\
Returns to scale & $\theta$ & 0.85 \\
Elasticity of substitution between capital and labor & $\phi$ & 0.50 \\
Rate of depreciation for capital & $\delta_{k}$ & 0.01 \\
Quit rate of labor & $\delta_{n}$ & 0.01 \\
Fixed operating cost & $f$ & 0.0105 \\
Worker's productivity & $\lambda$ & 1 \\
Technology: adjustment costs & & \\
Convex parameters in capital adjustment cost & $c_{k}^{+} / c_{k}^{-}$ & $3.1 / 34.1$ \\
Convex parameters in labor adjustment cost & $c_{n}^{+} / c_{n}^{-}$ & $1.2 / 1.2$ \\
Nonconvex parameters in capital adjustment cost & $b_{k}^{+} / b_{k}^{-}$ & $.04 / .08$ \\
Nonconvex parameters in labor adjustment cost & $b_{n}^{+} / b_{n}^{-}$ & $0.16 / 0.20$ \\
Stochastic processes & & \\
Multiplicative coefficient on wage rate process & $\tau_{1}$ & .0095 \\
Sensitivity of the wage rate to aggregate productivity & $\tau_{2}$ & 0.9 \\
Average growth rate of aggregate productivity & $\mu_{x}$ & $0.013 / 12$ \\
Conditional volatility of aggregate productivity & $\sigma_{x}$ & 0.055 \\
Average level of firm-specific productivity & $\bar{z}$ & -3.4 \\
Persistence coefficient of firm-specific productivity & $\rho_{z}$ & 0.97 \\
Conditional volatility of firm-specific productivity & $\sigma_{z}$ & 0.10 \\
Persistence coefficient of adjustment cost wedge & $\rho_{s}$ & 0.97 \\
Conditional volatility of adjustment cost wedge & $\sigma_{s}$ & 0.035 \\
Real risk-free rate (\%) & $r_{f}$ & $1.65 / 12$ \\
Loading of the SDF on aggregate productivity shock & $\gamma_{x}$ & 6.75 \\
Loading of the SDF on the adjustment cost shock & $\gamma_{s}$ & -14.5 \\
\hline
\end{tabular}


Table 2: Model predictions: selected moments across alternative calibrations

This table presents the selected moments of asset prices and real quantities in alternative calibrations of the model (columns 1 to 4) and in the real data (column 5). BLB corresponds to the homogeneous economy calibration in Belo, Lin, and Bazdresch (2014). We compare the moments in the data with moments of simulated data. The model-implied moments are the mean value of the corresponding moments across simulations. Rows 1 to 6 report the return properties of the hiring (HN) low minus high (spread) portfolio in the high skill industry and in the low skill industry. The hiring return spread is the average returns of the 5 th quintile minus 1st quintile hiring rate portfolio. Excess return is the annualized $(\times 1200)$ portfolio excess return (in excess of the risk free rate). Sharpe ratio is the HN spread portfolio Sharpe ratio (mean excess return-to-standard deviation of excess returns ratio). CAPM alpha is the intercept from monthly CAPM regressions, reported in annual percentage $(\times 1200)$. Rows 7 to 11 report the ratio of the moments of selected variables in the high skill relative to the low skill industry (denoted h/l). S.D. $(\Delta \text { Sales })^{\mathrm{h} / \mathrm{l}}, \mathrm{S} . \mathrm{D} .(\Delta \mathrm{Wage})^{\mathrm{h} / \mathrm{l}}$, S.D. $(\mathrm{HN})^{\mathrm{h} / \mathrm{l}}$, S.D. $(\mathrm{IK})^{\mathrm{h} / \mathrm{l}}$ are the ratio of the standard deviation of firm-level real sales growth $(\Delta$ Sales), real wages $(\Delta$ Wages), hiring rate $(\mathrm{HN})$, investment rate $(\mathrm{IK})$, respectively in the high skill industry relative to the standard deviation of the same variables in the the low skill industry. Mean(Wage) ${ }^{\mathrm{s} / 1}$ is the ratio of the mean real wage rate in the high skill industry relative to the mean real wage rate in the low skill industry. The real data are from 1991 to 2012. The reported statistics for the model are obtained from 500 samples of simulated data, each with 1,500 firms and 600 monthly observations for each industry.

\begin{tabular}{|c|c|c|c|c|c|c|}
\hline Row & Moments & BLB & Adj. cost & $\begin{array}{l}\text { Adj. cost } \\
\text { \& vol. } \\
(3)\end{array}$ & $\begin{array}{c}\text { Adj cost, } \\
\text { vol. \& } \\
\text { wage } \\
(4)\end{array}$ & Data \\
\hline & Asset prices: HN spread portfolio & & & & & \\
\hline 1 & Excess return (\%) - High skill & 4.38 & 5.29 & 5.24 & 5.16 & 8.55 \\
\hline 2 & Excess return (\%) - Low skill & 4.38 & 1.23 & 0.90 & 0.21 & 2.66 \\
\hline 3 & Sharpe ratio - High skill & 1.05 & 1.09 & 0.97 & 0.95 & 0.77 \\
\hline 4 & Sharpe ratio - Low skill & 1.05 & 0.18 & 0.19 & 0.04 & 0.31 \\
\hline 5 & CAPM alpha (\%) - High skill & 5.17 & 7.21 & 6.47 & 6.46 & 10.44 \\
\hline 6 & CAPM alpha (\%) - Low skill & 5.17 & 2.77 & 2.28 & 2.28 & 2.30 \\
\hline & Relative quantities and wages & & & & & \\
\hline 7 & S.D. $(\Delta \text { Sales })^{\mathrm{h} / \mathrm{l}}$ & 1 & 0.72 & 1.31 & 1.37 & 1.24 \\
\hline 8 & Mean $(\text { Wage })^{\mathrm{h} / \mathrm{l}}$ & 1 & 1 & 1 & 1.38 & 1.38 \\
\hline 9 & S.D. $(\Delta \text { Wage })^{\mathrm{h} / \mathrm{l}}$ & 1 & 1 & 1 & 0.76 & 0.62 \\
\hline 10 & S.D. $(\mathrm{HN})^{\mathrm{h} / \mathrm{l}}$ & 1 & 0.68 & 1 & 1.16 & 1.04 \\
\hline 11 & S.D. $(\mathrm{IK})^{\mathrm{h} / \mathrm{l}}$ & 1 & 0.96 & 1.19 & 1.19 & 1.33 \\
\hline
\end{tabular}


Table 3: Industries with highest and lowest average labor skills

This table presents the top 10 (Panel A) and bottom 10 (Panel B) industries sorted on average labor skill in 2012. Industry average labor skill (Skill, in percentage) is measured as the industry-level proportion of workers in occupations that have a Specific Vocational Preparation (SVP) value of 7, 8, or 9. An industry is defined at the four-digit NAICS level.

\begin{tabular}{llc}
\hline \hline NAICS & \multicolumn{1}{c}{ Industry } & Skill (\%) \\
\hline & & \\
\hline 5112 & Panel A: 10 Industries with highest average skills & 76.5 \\
5415 & Computer Systems Design and Related Services & 71.9 \\
3341 & Computer and Peripheral Equipment Manufacturing & 70.4 \\
5417 & Scientific Research and Development Services & 67.9 \\
5413 & Architectural, Engineering, and Related Services & 65.9 \\
5414 & Specialized Design Services & 63.9 \\
5232 & Securities and Commodity Exchanges & 63.4 \\
6111 & Elementary and Secondary Schools & 62.1 \\
6113 & Colleges, Universities, and Professional Schools & 61.1 \\
6112 & Junior Colleges & 60.0 \\
& & \\
& Panel B: 10 Industries with lowest average skills & 1.3 \\
\hline 7225 & Restaurants and Other Eating Places & 1.4 \\
4481 & Clothing Stores & 1.4 \\
4482 & Shoe Stores & 1.4 \\
4531 & Florists & 1.5 \\
4471 & Gasoline Stations & 1.5 \\
4854 & School and Employee Bus Transportation & 1.7 \\
8121 & Personal Care Services & 2.1 \\
7224 & Drinking Places (Alcoholic Beverages) & 2.1 \\
4452 & Specialty Food Stores & 2.3 \\
4533 & Used Merchandize Stores & \\
\hline & &
\end{tabular}


Table 4: Firm characteristics in low and high labor skill industries

This table reports the average portfolio characteristics of 2 one-way sorted (Low and High) on labor skill portfolios (top Panel), and 10 two-way sorted on labor skill (Low and High) and labor hiring (HN, from 1-Low to 5-High) portfolios (medium and bottom Panels). We split the firms into low and high labor skill industries based on the median value of the industry-level labor skill variable in the cross-section in each year. Skill is the fraction of workers in high skill industries; Age is the firm age measured as the number of years since the firm is included in CRSP; HN in the (net) hiring rate; IK is the physical capital investment rate; $\Delta$ Sales is the real growth rate in sales; Size is the log market equity; BM is the book-to-market ratio; $\mathrm{KL}$ is the real physical capital stock to employee ratio; R\&D is the research and development to sales ratio (in percentage). All measures are annual. H-L stands for high-minus-low. The portfolio-level characteristic is the time series average of the median characteristic across the firms in the portfolio in each year. The sample is from 1991 to 2012 .

\begin{tabular}{|c|c|c|c|c|c|c|c|c|c|}
\hline \multicolumn{10}{|l|}{ Portfolio sort } \\
\hline Skill Hiring & Skill & Age & $\mathrm{HN}$ & IK & $\Delta$ Sales & Size & $\mathrm{BM}$ & $\mathrm{KL}$ & $\mathrm{R} \& \mathrm{D}$ \\
\hline
\end{tabular}

Two labor skill portfolios

\begin{tabular}{|c|c|c|c|c|c|c|c|c|c|c|}
\hline Low & & 0.10 & 11.55 & 0.02 & 0.18 & 0.04 & 5.40 & 0.64 & 0.18 & 0.28 \\
\hline High & & 0.32 & 9.30 & 0.04 & 0.22 & 0.07 & 5.45 & 0.53 & 0.19 & 7.81 \\
\hline & H-L & 0.21 & -2.25 & 0.02 & 0.05 & 0.03 & 0.05 & -0.11 & 0.01 & 7.53 \\
\hline & {$[\mathrm{t}]$} & 17.16 & -4.33 & 4.62 & 6.92 & 6.03 & 0.56 & -2.96 & 1.77 & 8.92 \\
\hline
\end{tabular}

Five hiring portfolios in low labor skill industries

\begin{tabular}{llrrrrrrrrr}
\hline Low & Low & 0.10 & 13.41 & -0.15 & 0.13 & -0.07 & 4.64 & 0.91 & 0.17 & 0.48 \\
Low & 2 & 0.10 & 15.63 & -0.03 & 0.15 & -0.01 & 5.60 & 0.73 & 0.23 & 0.43 \\
Low & 3 & 0.10 & 15.26 & 0.02 & 0.17 & 0.03 & 5.83 & 0.63 & 0.22 & 0.47 \\
Low & 4 & 0.10 & 12.59 & 0.09 & 0.22 & 0.09 & 5.64 & 0.58 & 0.18 & 0.25 \\
Low & High & 0.10 & 9.04 & 0.28 & 0.29 & 0.20 & 5.48 & 0.51 & 0.16 & 0.08 \\
\hline & H-L & -0.01 & -4.37 & 0.43 & 0.17 & 0.27 & 0.84 & -0.40 & -0.02 & -0.40 \\
& {$[\mathrm{t}]$} & -1.73 & -3.36 & 11.98 & 8.33 & 13.11 & 6.32 & -7.06 & -1.94 & -4.78
\end{tabular}

Five hiring portfolios in high labor skill industries

\begin{tabular}{llrrrrrrrrr}
\hline High Low & 0.33 & 10.81 & -0.17 & 0.16 & -0.09 & 4.61 & 0.71 & 0.19 & 9.16 \\
High & 2 & 0.29 & 14.20 & -0.03 & 0.17 & 0.01 & 5.62 & 0.64 & 0.22 & 4.48 \\
High & 3 & 0.29 & 13.07 & 0.04 & 0.21 & 0.06 & 5.79 & 0.56 & 0.21 & 5.65 \\
High & 4 & 0.32 & 9.60 & 0.13 & 0.29 & 0.13 & 5.68 & 0.47 & 0.19 & 8.51 \\
High & High & 0.34 & 7.02 & 0.35 & 0.40 & 0.30 & 5.63 & 0.40 & 0.17 & 11.44 \\
\hline & H-L & 0.01 & -3.79 & 0.52 & 0.25 & 0.39 & 1.02 & -0.31 & -0.03 & 2.28 \\
& {$[\mathrm{t}]$} & 1.29 & -4.94 & 12.42 & 13.04 & 11.41 & 8.91 & -7.13 & -5.00 & 1.83 \\
\hline
\end{tabular}


Table 5: Panel OLS regressions

The table reports the slope coefficients from pooled firm-level ols regressions to predict annual stock returns of the form:

$$
r_{i, t}=a_{t}+b_{i}+c \times \mathrm{HN}_{t-1}+d \times \mathrm{HN}_{t-1} \times \text { HSkill }_{t-1}+e \times \text { HSkill }_{t-1}+\text { controls }_{t-1}+\mathrm{e}_{i t},
$$

in which the subscripts $i$ stand for firm $i=1, \ldots N$, and $t$ stands for time $t=1, \ldots T$. The explained variable is $r$, the firm's $i$ future annual log stock return from July of year $t$ to June of year $t+1$. The explanatory variables are the following: $a_{t}$ is a time fixed effect (Year FE, if included); $b_{i}$ is a firm fixed effect (Firm FE, if included); HN, is the firms' lagged hiring rate; HSkill is a dummy variable which is one if the firm belong to a high skill industry at the end of fiscal year end t-2; Micro is a dummy variable which is one if the firm is classified as a micro cap firm (market equity below the 20th percentile of the cross sectional distribution of market equity of NYSE firms) at the end of fiscal year end t-2. The additional control variables are: IK, is the firms' lagged physical investment rate; Size is the firm's lagged log market capitalization; BM is the firms' lagged log book-to-market ratio; and Lev is the firm's lagged leverage ratio. $\mathrm{N}$ is the number of observations. $R^{2}$ is adjusted for degrees of freedom. The t-statistic of each coefficient is reported in parenthesis and is computed from standard errors clustered by firm. To decrease the influence of outliers, the firm-level investment rate is winsorized at the top and bottom $0.5 \%$ in each cross-section. The sample is from 1991 to 2012.

\begin{tabular}{|c|c|c|c|c|c|c|c|c|c|c|}
\hline \multicolumn{2}{|l|}{$\overline{\text { Row }}$} & (1) & $\overline{(2)}$ & 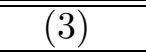 & (4) & $\overline{(5)}$ & (6) & (7) & $(8)$ & $(9)$ \\
\hline 1 & $\overline{\mathrm{HN}}$ & $\begin{array}{l}-11.54 \\
(-4.68)\end{array}$ & $\begin{array}{r}-8.49 \\
(-310)\end{array}$ & -11.35 & $\begin{array}{l}-15.91 \\
(-445)\end{array}$ & $\begin{array}{r}-7.61 \\
(-3.10)\end{array}$ & -5.69 & $\begin{array}{r}-7.27 \\
(-210)\end{array}$ & -13.13 & $\begin{array}{r}1.506 \\
(0.43)\end{array}$ \\
\hline 2 & $\mathrm{HN} \times$ HSkill & -8.16 & -13.68 & -14.67 & -19.52 & -7.33 & -12.41 & -12.94 & -18.15 & -14.43 \\
\hline 3 & HSkill & -0.65 & & 0.77 & & 0.34 & & 1.48 & & \\
\hline 4 & Micro & $(-0.99)$ & & $\begin{array}{r}(1.06) \\
-3.92 \\
(-3.63)\end{array}$ & & $(0.51)$ & & $\begin{array}{r}(2.04) \\
-3.81 \\
(-3.53)\end{array}$ & & \\
\hline 5 & $\mathrm{HN} \times$ Micro & & & $\begin{array}{r}-0.88 \\
(-0.19)\end{array}$ & $\begin{array}{l}11.51 \\
(2.34)\end{array}$ & & & $\begin{array}{r}-1.30 \\
(-0.28)\end{array}$ & $\begin{array}{l}11.43 \\
(2.34)\end{array}$ & $\begin{array}{r}5.07 \\
(1.06)\end{array}$ \\
\hline 6 & HSkill $\times$ Micro & & & $\begin{array}{r}-2.40 \\
(-1.92)\end{array}$ & & & & $\begin{array}{r}-1.99 \\
(-1.59)\end{array}$ & & \\
\hline 7 & $\mathrm{HN} \times$ HSkill $\times$ Micro & & & $\begin{array}{r}9.98 \\
(1.84)\end{array}$ & $\begin{array}{r}10.30 \\
(1.79)\end{array}$ & & & $\begin{array}{r}8.46 \\
(1.56)\end{array}$ & $\begin{array}{r}10.18 \\
(1.78)\end{array}$ & $\begin{array}{r}6.02 \\
(1.09)\end{array}$ \\
\hline 8 & IK & & & & & $\begin{array}{r}-16.81 \\
(-12.62)\end{array}$ & $\begin{array}{r}-19.32 \\
(-11.14)\end{array}$ & $\begin{array}{r}-16.18 \\
(-12.23)\end{array}$ & $\begin{array}{r}-19.21 \\
(-11.11)\end{array}$ & $\begin{array}{r}-9.72 \\
(-5.68)\end{array}$ \\
\hline 9 & Size & & & & & & & & & $\begin{array}{r}-25.66 \\
(-37.15)\end{array}$ \\
\hline 10 & $\mathrm{BM}$ & & & & & & & & & $\begin{array}{r}1.882 \\
(2.71)\end{array}$ \\
\hline 11 & Lev & & & & & & & & & $\begin{array}{l}-11.21 \\
(-3.70)\end{array}$ \\
\hline & Year FE & Yes & Ye: & Yes & Yes & Yes & $\overline{\mathrm{Ye}}$ & $\overline{\text { Yes }}$ & Yes & Yes \\
\hline & Firm FE & & Yes & & Yes & & Yes & & Yes & Yes \\
\hline & $N$ & 44938 & 44074 & 44922 & 44059 & 44905 & 44040 & 44889 & 44025 & 43769 \\
\hline & $R^{2}$ & 0.110 & 0.010 & 0.112 & 0.012 & 0.115 & 0.014 & 0.117 & 0.017 & 0.111 \\
\hline
\end{tabular}


Table 6: Labor skill and the hiring return spread

This table reports the average excess stock returns and abnormal returns of five one-way sorted on labor hiring rate portfolios across firms belonging to industries classified as low skilled labor industries (left panel), and across firms belonging to industries classified as high skilled labor (right panel). The split the firms into low and high skill industries is based on the median value of the industry-level labor skill variable in the cross-section in each year. $r^{e}$ is the average annualized $(\times 1200)$ portfolio excess stock return; $[t]$ are heteroscedasticity and autocorrelation consistent $t$-statistics (Newey-West); SR is the portfolio Sharpe ratio, $\alpha$ is portfolio average abnormal return, obtained as the intercept from monthly CAPM, reported in annual percentage $(\times 1200)$; L-H stands for the low-minus-high hiring portfolio; Diff L-H stands for the difference in the L-H in high labor skill industries and low labor skill industries. The sample is from July 1991 to December 2012.

\begin{tabular}{|c|c|c|c|c|c|c|c|c|c|c|c|c|c|}
\hline & \multicolumn{6}{|c|}{ Low skill industries } & \multicolumn{6}{|c|}{ High skill industries } & \multirow{2}{*}{$\begin{array}{l}\text { Diff } \\
\text { L-H }\end{array}$} \\
\hline & $\mathrm{L}$ & 2 & 3 & 4 & $\mathrm{H}$ & $\mathrm{L}-\mathrm{H}$ & $\mathrm{L}$ & 2 & 4 & 4 & $\mathrm{H}$ & L-H & \\
\hline & \multicolumn{13}{|c|}{ Excess returns } \\
\hline$r^{e}$ & 7.86 & 8.10 & 6.01 & 7.50 & 5.21 & 2.66 & 11.13 & 9.53 & 8.02 & 9.64 & 2.58 & 8.55 & 5.89 \\
\hline$[\mathrm{t}]$ & 1.64 & 2.20 & 1.75 & 2.02 & 1.22 & 1.06 & 2.92 & 2.95 & 2.34 & 2.40 & 0.54 & 2.65 & 1.76 \\
\hline SR & 0.47 & 0.63 & 0.50 & 0.58 & 0.35 & 0.31 & 0.84 & 0.85 & 0.67 & 0.69 & 0.16 & 0.77 & 0.46 \\
\hline \multicolumn{14}{|c|}{ CAPM abnormal returns } \\
\hline$\alpha$ & 0.20 & 2.00 & 0.27 & 1.17 & -2.10 & 2.30 & 4.23 & 3.57 & 1.40 & 1.94 & -6.21 & 10.44 & 8.14 \\
\hline$[\mathrm{t}]$ & 0.07 & 0.87 & 0.13 & 0.57 & -0.90 & 0.91 & 2.31 & 2.47 & 1.21 & 1.39 & -2.84 & 3.18 & 2.51 \\
\hline$b$ & 1.14 & 0.91 & 0.85 & 0.94 & 1.09 & 0.05 & 1.03 & 0.89 & 0.99 & 1.15 & 1.31 & -0.28 & -0.33 \\
\hline$[\mathrm{t}]$ & 14.28 & 14.94 & 16.43 & 17.09 & 17.64 & 0.89 & 22.30 & 24.16 & 36.91 & 37.59 & 26.01 & -3.37 & -4.19 \\
\hline
\end{tabular}


Table 7: Cross sectional regressions

The table shows average slope coefficients and their heteroscedasticity-and-autocorrelation-consistent $t$-statistics (Newey-West) (in parenthesis) from monthly firm-level cross-section regressions of the form:

$$
r_{i t}=\mathrm{Int}_{t}+\mathrm{a}_{t} \times \mathrm{HN}_{i t-1}+\mathrm{b}_{t} \times \mathrm{HN}_{i t-1} \times \text { Micro }_{t-1}+\operatorname{controls}_{t-1}+e_{i t},
$$

in which the subscripts $i$ stand for firm $i=1, . . N_{t}$, and $t$ stands for time $t=1, . ., T$. The explained variable is $r$, the firm's $i$ future monthly log stock return. Depending on the specification (from 1 to 5 ), the explanatory variables are: HN, is the firms' lagged hiring rate; Micro is a dummy variable which is one if the firm is classified as a micro cap firm (market equity below the 20th percentile of the cross sectional distribution of market equity of NYSE firms) at the end of fiscal year end t-2. The additional controls are: IK, is the firms' lagged physical investment rate; Size is the firm's lagged $\log$ market capitalization; BM is the firms' lagged log book-to-market ratio; Lev is the firm's lagged leverage ratio. $R^{2}$ is time series average of the regression $\mathrm{R}^{2}$ adjusted for degrees of freedom. To decrease the influence of outliers, the firm-level investment rate is winsorized at the top and bottom $0.5 \%$ in each cross-section. Each specification of the regression is estimated separately across two samples: L (Low) includes only firms in low skill labor industries at the end of fiscal year-end t-2 and $\mathrm{H}$ (High) includes only firms in high skill labor industries at the end fo fiscal year-end t-2. The columns H-L test for the difference in the average estimated slope coefficients in the high (H) and low (L) labor skill industries. The stock returns data are monthly, the accounting data are annual, and the sample is from July 1991 to December 2012.

\begin{tabular}{|c|c|c|c|c|c|c|c|c|c|c|c|c|c|c|c|c|}
\hline \multirow[b]{2}{*}{ Row } & & \multicolumn{3}{|c|}{ (1) } & \multicolumn{3}{|c|}{ (2) } & \multicolumn{3}{|c|}{ (3) } & \multicolumn{3}{|c|}{ (4) } & \multicolumn{3}{|c|}{ (5) } \\
\hline & & $\mathrm{L}$ & $\mathrm{H}$ & H-L & $\mathrm{L}$ & $\mathrm{H}$ & H-L & $\mathrm{L}$ & $\mathrm{H}$ & H-L & $\bar{L}$ & $\mathrm{H}$ & H-L & $\mathrm{L}$ & $\mathrm{H}$ & H-L \\
\hline 1 & $\mathrm{HN}$ & 0.10 & -1.37 & -1.47 & -0.60 & -1.97 & -1.38 & 0.39 & -0.94 & -1.33 & 0.32 & -1.10 & -1.43 & -0.11 & -1.30 & -1.19 \\
\hline & & $(0.31)$ & $-5.40)$ & $(-4.40)$ & $(-1.75)$ & $-5.35)$ & $(-3.46)$ & $(1.23)$ & $(-4.35)$ & $(-4.05)$ & $(1.04)$ & $(-5.68)$ & $(-4.42)$ & $(-0.33)$ & $(-4.84)$ & $(-3.26)$ \\
\hline 2 & Micro & & & & $\begin{array}{r}-0.99 \\
(-4.59)\end{array}$ & $\begin{array}{r}-1.06 \\
-4.24)\end{array}$ & $\begin{array}{r}-0.07 \\
(-0.44)\end{array}$ & & & & & & & $\begin{array}{r}0.19 \\
(1.01)\end{array}$ & $\begin{array}{r}-0.10 \\
(-0.60)\end{array}$ & $\begin{array}{r}-0.30 \\
(-1.46)\end{array}$ \\
\hline 3 & $\mathrm{HN} \times$ Micro & & & & $\begin{array}{r}0.87 \\
(2.06)\end{array}$ & $\begin{array}{r}0.80 \\
(2.21)\end{array}$ & $\begin{array}{r}-0.07 \\
(-0.13)\end{array}$ & & & & & & & $\begin{array}{r}0.62 \\
(1.52)\end{array}$ & $\begin{array}{r}0.34 \\
(1.07)\end{array}$ & $\begin{array}{r}-0.28 \\
(-0.56)\end{array}$ \\
\hline 4 & IK & & & & & & & $\begin{array}{r}-1.15 \\
(-3.06)\end{array}$ & $\begin{array}{r}-1.17 \\
(-3.40)\end{array}$ & $\begin{array}{l}-0.03 \\
(-0.07)\end{array}$ & $\begin{array}{r}-1.60 \\
(-4.18)\end{array}$ & $\begin{array}{r}-1.32 \\
(-4.73)\end{array}$ & $\begin{array}{r}0.28 \\
(0.75)\end{array}$ & $\begin{array}{r}-1.60 \\
(-4.19)\end{array}$ & $\begin{array}{r}-1.28 \\
(-4.81)\end{array}$ & $\begin{array}{r}0.32 \\
(0.86)\end{array}$ \\
\hline 5 & Size & & & & & & & & & & $\begin{array}{r}1.77 \\
(5.37)\end{array}$ & $\begin{array}{r}1.73 \\
(5.01)\end{array}$ & $\begin{array}{r}-0.04 \\
(-0.15)\end{array}$ & $\begin{array}{r}1.95 \\
(5.03)\end{array}$ & $\begin{array}{r}1.64 \\
(4.85)\end{array}$ & $\begin{array}{r}-0.31 \\
(-0.96)\end{array}$ \\
\hline 6 & $\mathrm{BM}$ & & & & & & & & & & $\begin{array}{r}0.49 \\
(5.83)\end{array}$ & $\begin{array}{r}0.54 \\
(6.07)\end{array}$ & $\begin{array}{r}0.05 \\
(0.46)\end{array}$ & $\begin{array}{r}0.49 \\
(5.81)\end{array}$ & $\begin{array}{r}0.54 \\
(6.10)\end{array}$ & $\begin{array}{r}0.05 \\
(0.48)\end{array}$ \\
\hline 7 & Lev & & & & & & & & & & $\begin{array}{r}-2.09 \\
(-5.09)\end{array}$ & $\begin{array}{r}-1.46 \\
(-4.32)\end{array}$ & $\begin{array}{r}0.63 \\
(1.43)\end{array}$ & $\begin{array}{r}-2.11 \\
(-5.13)\end{array}$ & $\begin{array}{r}-1.46 \\
(-4.38)\end{array}$ & $\begin{array}{r}0.64 \\
(1.47)\end{array}$ \\
\hline & $\overline{\mathrm{R}^{2}}$ & 0.56 & 0.40 & & 1.77 & 1.50 & & 1.05 & 0.91 & & 3.75 & 2.93 & & 4.34 & 4.34 & \\
\hline
\end{tabular}


Table 8: Evidence from a long sample

This table replicates the analysis in Table 5 in the longer (non-tradable) sample from 1963 to 2012. The sample is extended backwards from 1991 to 1963 by assuming that our labor skill measure for each three-digit SIC industry during this period is equal to the average labor skill measure for the same three-digit SIC industry between 1991 and 2001.

\begin{tabular}{|c|c|c|c|c|c|c|c|c|c|c|}
\hline \multirow{2}{*}{$\frac{\text { Row }}{1}$} & & $(1)$ & (2) & (3) & $(4)$ & $(5)$ & $(6)$ & $(7)$ & $(8)$ & $(9)$ \\
\hline & $\mathrm{HN}$ & $\begin{array}{l}-10.47 \\
(-6.36)\end{array}$ & $\begin{array}{r}-9.46 \\
(-5.48)\end{array}$ & $\begin{array}{l}-11.83 \\
(-4.97)\end{array}$ & $\begin{array}{l}-14.71 \\
(-5.94)\end{array}$ & $\begin{array}{r}-6.97 \\
(-4.20)\end{array}$ & $\begin{array}{r}-6.85 \\
(-3.96)\end{array}$ & $\begin{array}{r}-7.94 \\
(-3.32)\end{array}$ & $\begin{array}{l}-11.95 \\
(-4.89)\end{array}$ & $\begin{array}{r}0.230 \\
(0.09)\end{array}$ \\
\hline 2 & $\mathrm{HN} \times$ HSkill & $\begin{array}{r}-5.68 \\
(-2.86)\end{array}$ & $\begin{array}{r}-7.98 \\
(-3.82)\end{array}$ & $\begin{array}{l}-10.17 \\
(-3.51)\end{array}$ & $\begin{array}{l}-14.33 \\
(-4.73)\end{array}$ & $\begin{array}{r}-4.89 \\
(-2.45)\end{array}$ & $\begin{array}{r}-7.09 \\
(-3.40)\end{array}$ & $\begin{array}{r}-8.94 \\
(-3.08)\end{array}$ & $\begin{array}{l}-13.53 \\
(-4.53)\end{array}$ & $\begin{array}{l}-12.41 \\
(-4.19)\end{array}$ \\
\hline 3 & HSkill & $\begin{array}{r}-0.28 \\
(-0.63)\end{array}$ & & $\begin{array}{r}0.28 \\
(0.58)\end{array}$ & & $\begin{array}{r}0.34 \\
(0.77)\end{array}$ & & $\begin{array}{r}0.70 \\
(1.45)\end{array}$ & & \\
\hline 4 & Micro & & & $\begin{array}{r}-4.25 \\
(-6.24)\end{array}$ & & & & $\begin{array}{r}-4.24 \\
(-6.24)\end{array}$ & & \\
\hline 5 & $\mathrm{HN} \times$ Micro & & & $\begin{array}{r}1.21 \\
(0.39)\end{array}$ & $\begin{array}{r}7.64 \\
(2.33)\end{array}$ & & & $\begin{array}{r}0.49 \\
(0.16)\end{array}$ & $\begin{array}{l}7.378 \\
(2.27)\end{array}$ & $\begin{array}{r}1.00 \\
(0.31)\end{array}$ \\
\hline 6 & HSkill ×Micro & & & $\begin{array}{r}-1.33 \\
(-1.61)\end{array}$ & & & & $\begin{array}{r}-0.99 \\
(-1.20)\end{array}$ & & \\
\hline 7 & $\mathrm{HN} \times$ HSkill $\times$ Micro & & & $\begin{array}{r}7.20 \\
(1.88)\end{array}$ & $\begin{array}{l}10.93 \\
(2.74)\end{array}$ & & & $\begin{array}{r}6.39 \\
(1.67)\end{array}$ & $\begin{array}{r}11.04 \\
(2.79)\end{array}$ & $\begin{array}{r}9.88 \\
(2.55)\end{array}$ \\
\hline 8 & IK & & & & & $\begin{array}{r}-15.16 \\
(-14.57)\end{array}$ & $\begin{array}{r}-16.6 \\
(-13.26)\end{array}$ & $\begin{array}{r}-14.68 \\
(-14.22)\end{array}$ & $\begin{array}{r}-16.48 \\
(-13.16)\end{array}$ & $\begin{array}{r}-8.56 \\
(-6.87)\end{array}$ \\
\hline 9 & Size & & & & & & & & & $\begin{array}{r}-18.57 \\
(-35.70)\end{array}$ \\
\hline 10 & $\mathrm{BM}$ & & & & & & & & & $\begin{array}{r}3.89 \\
(8.11)\end{array}$ \\
\hline 11 & Lev & & & & & & & & & $\begin{array}{l}-15.76 \\
(-7.94)\end{array}$ \\
\hline & Year FE & Yes & Yes & Yes & Yes & Yes & Yes & Yes & Yes & Yes \\
\hline & Firm FE & & Yes & & Yes & & Yes & & Yes & Yes \\
\hline & $N$ & 75927 & 74905 & 75838 & 74813 & 75891 & 74868 & 75802 & 74776 & 73472 \\
\hline & $R^{2}$ & 0.155 & 0.007 & 0.157 & 0.009 & 0.159 & 0.011 & 0.161 & 0.013 & 0.083 \\
\hline
\end{tabular}


Table 9: Evidence from international data

This table replicates the analysis in Table 5 using international data for the G6 countries (Canada, France, Germany, Italy, Japan, and United Kingdom). The table reports the slope coefficients from pooled firm-level ols regressions to predict annual stock returns of the form:

$$
r_{i, z, t}=a_{t, z}+b_{i}+c \times \mathrm{HN}_{t-1}+d \times \mathrm{HN}_{t-1} \times \text { HSkill }_{t-1}+e \times \text { HSkill }_{t-1}+\text { controls }_{t-1}+\mathrm{e}_{i t},
$$

in which the subscripts $i$ stand for firm $i=1, . . N, z$ stands for country $c=1, . ., 6$, and $t$ stands for time $t=1, . ., T$. The explained variable is $r$, the firm's $i$ future annual log stock return from July of year $\mathrm{t}$ to June of year $\mathrm{t}+1$ (expressed in dollars). The explanatory variables are the following: $\mathrm{a}_{t, z}$ is a country $\times$ time fixed effect (Country $\times$ Year FE); $\mathrm{b}_{i}$ is a firm fixed effect (Firm FE, if included); HN, is the firms' lagged hiring rate; HSkill is a dummy variable which is one if the firm belong to a high skill industry at the end of fiscal year end t-2; Micro is a dummy variable which is one if the firm is classified as a micro cap firm (market equity below the 20th percentile of the cross sectional distribution of market equity of all international firms included in the sample) at the end of fiscal year end t-2. The additional control variables is the IK, the firms' lagged physical investment rate. $\mathrm{N}$ is the number of observations. $R^{2}$ is adjusted for degrees of freedom. The t-statistic of each coefficient is reported in parenthesis and is computed from standard errors clustered by firm. To decrease the influence of outliers, the firm-level investment rate is winsorized at the top and bottom $0.5 \%$ in each cross-section. The sample is from 1992 to 2012.

\begin{tabular}{|c|c|c|c|c|c|c|c|c|c|}
\hline \multicolumn{2}{|l|}{ Row } & (1) & $(2)$ & (3) & (4) & (5) & (6) & (7) & (8) \\
\hline \multirow[t]{2}{*}{1} & $\mathrm{HN}$ & -6.43 & -9.84 & -8.80 & -10.87 & -4.42 & -9.35 & -5.78 & -9.24 \\
\hline & & $(-3.18)$ & $(-4.29)$ & $(-4.03)$ & $(-4.55)$ & $(-2.31)$ & $(-4.28)$ & $(-2.59)$ & $(-3.68)$ \\
\hline \multirow[t]{2}{*}{2} & $\mathrm{HN} \times$ HSkill & -8.21 & -6.66 & -8.56 & -6.67 & -5.99 & -4.97 & -7.07 & -6.22 \\
\hline & & $(-3.35)$ & $(-2.40)$ & $(-3.14)$ & $(-2.23)$ & $(-2.53)$ & $(-1.83)$ & $(-2.55)$ & $(-2.00)$ \\
\hline \multirow[t]{2}{*}{3} & HSkill & -1.30 & & -1.39 & & -0.46 & & -0.64 & \\
\hline & & $(-3.56)$ & & $(-3.52)$ & & $(-1.26)$ & & $(-1.60)$ & \\
\hline \multirow[t]{2}{*}{4} & Micro & & & -1.48 & & & & -1.45 & \\
\hline & & & & $(-2.14)$ & & & & $(-2.06)$ & \\
\hline \multirow[t]{2}{*}{5} & $\mathrm{HN} \times$ Micro & & & 10.13 & 6.29 & & & 5.94 & 1.79 \\
\hline & & & & $(1.88)$ & $(0.99)$ & & & $(1.32)$ & $(0.36)$ \\
\hline \multirow[t]{2}{*}{6} & HSkill $\times$ Micro & & & 0.49 & & & & 0.92 & \\
\hline & & & & $(0.53)$ & & & & $(0.98)$ & \\
\hline \multirow[t]{2}{*}{7} & $\mathrm{HN} \times$ HSkill $\times$ Micro & & & 1.41 & -3.39 & & & 4.96 & 2.12 \\
\hline & & & & $(0.23)$ & $(-0.46)$ & & & $(0.91)$ & $(0.34)$ \\
\hline \multirow[t]{6}{*}{8} & IK & & & & & -13.39 & -12.69 & -13.17 & -12.74 \\
\hline & & & & & & $(-12.46)$ & $(-9.22)$ & $(-12.23)$ & $(-9.20)$ \\
\hline & Country $\times$ Year FE & Yes & Yes & Yes & Yes & Yes & Yes & Yes & Yes \\
\hline & Firm FE & & Yes & & Yes & & Yes & & Yes \\
\hline & $N$ & 53233 & 52462 & 52064 & 51304 & 51152 & 50370 & 50025 & 49252 \\
\hline & $R^{2}$ & 0.208 & 0.007 & 0.212 & 0.007 & 0.219 & 0.011 & 0.223 & 0.012 \\
\hline
\end{tabular}


Table 10: Alternative portfolio procedures

This table replicates the analysis in Table 6 using alternative weights in the computation of the average returns of the hiring portfolios across low and high labor skill industries. For each procedure, the table reports the average excess stock returns, Sharpe ratios (SR), and CAPM abnormal returns of five oneway sorted on labor hiring rate portfolios across firms belonging to industries classified as low skilled labor industries (left panel), and across firms belonging to industries classified as high skilled labor (right panel). The split the firms into low and high skill industries is based on the median value of the industry-level labor skill variable in the cross-section in each year. All portfolios are one-year buy and hold so there is no rebalancing over the year. $r^{e}$ is the average annualized $(\times 1200)$ portfolio excess stock return; $[t]$ are heteroscedasticity and autocorrelation consistent $t$-statistics (Newey-West); $\alpha$ is portfolio average abnormal return, obtained as the intercept from monthly CAPM regressions, reported in annual percentage $(\times 1200)$. L-H stands for the low-minus-high hiring portfolio; Diff L-H stands for the difference in the L-H in high labor skill industries and low labor skill industries. The sample is from July 1991 to December 2012.

\begin{tabular}{|c|c|c|c|c|c|c|c|c|c|c|c|c|c|}
\hline & \multicolumn{6}{|c|}{ Low skill industries } & \multicolumn{6}{|c|}{ High skill industries } & \multirow{2}{*}{$\begin{array}{l}\text { Diff } \\
\text { L-H }\end{array}$} \\
\hline & $\mathrm{L}$ & 2 & 3 & 4 & $\mathrm{H}$ & $\mathrm{L}-\mathrm{H}$ & $\mathrm{L}$ & 2 & 3 & 4 & $\mathrm{H}$ & L-H & \\
\hline & \multicolumn{13}{|c|}{ Equal-weighted } \\
\hline$r^{e}$ & 8.71 & 9.05 & 10.03 & 9.50 & 5.51 & 3.20 & 14.98 & 12.72 & 11.92 & 10.72 & 4.85 & 10.13 & 6.93 \\
\hline$[\mathrm{t}]$ & 1.78 & 2.21 & 2.60 & 2.50 & 1.23 & 1.29 & 2.69 & 3.22 & 2.85 & 2.25 & 0.87 & 4.25 & 2.55 \\
\hline SR & 0.51 & 0.64 & 0.75 & 0.72 & 0.36 & 0.37 & 0.78 & 0.93 & 0.82 & 0.65 & 0.25 & 1.23 & 0.74 \\
\hline$a$ & 1.34 & 2.58 & 3.76 & 3.38 & -1.68 & 3.02 & 6.95 & 5.97 & 4.79 & 2.81 & -4.02 & 10.97 & 7.95 \\
\hline$[\mathrm{t}]$ & 0.41 & 0.99 & 1.58 & 1.39 & -0.62 & 1.23 & 1.81 & 2.75 & 2.13 & 1.05 & -1.19 & 4.60 & 3.01 \\
\hline \multicolumn{14}{|c|}{ All but micro equal-weighted } \\
\hline$r^{e}$ & 7.58 & 7.89 & 7.84 & 7.80 & 6.20 & 1.38 & 11.68 & 10.81 & 9.46 & 11.19 & 4.16 & 7.52 & 6.14 \\
\hline$[\mathrm{t}]$ & 1.62 & 2.03 & 2.10 & 1.97 & 1.39 & 0.60 & 2.80 & 3.00 & 2.47 & 2.42 & 0.78 & 2.54 & 2.13 \\
\hline SR & 0.47 & 0.58 & 0.61 & 0.57 & 0.40 & 0.17 & 0.81 & 0.87 & 0.71 & 0.70 & 0.23 & 0.73 & 0.61 \\
\hline$a$ & -0.02 & 1.52 & 1.65 & 1.31 & -1.30 & 1.29 & 4.08 & 4.22 & 2.24 & 3.06 & -5.20 & 9.28 & 8.00 \\
\hline$[\mathrm{t}]$ & -0.01 & 0.62 & 0.73 & 0.55 & -0.52 & 0.55 & 2.10 & 2.56 & 1.49 & 1.33 & -1.91 & 3.15 & 2.88 \\
\hline \multicolumn{14}{|c|}{ Number of employees-weighted } \\
\hline$r^{e}$ & 6.92 & 7.29 & 5.41 & 8.79 & 4.70 & 2.22 & 13.57 & 9.31 & 9.38 & 8.95 & 3.99 & 9.58 & 7.36 \\
\hline$[\mathrm{t}]$ & 1.22 & 1.67 & 1.29 & 2.15 & 1.09 & 0.60 & 3.09 & 2.48 & 2.52 & 2.34 & 0.97 & 3.64 & 1.81 \\
\hline SR & 0.35 & 0.48 & 0.37 & 0.62 & 0.32 & 0.17 & 0.89 & 0.72 & 0.73 & 0.67 & 0.28 & 1.05 & 0.52 \\
\hline$a$ & -0.97 & 0.68 & -0.74 & 2.35 & -2.09 & 1.12 & 6.20 & 2.79 & 2.64 & 1.77 & -3.50 & 9.70 & 8.58 \\
\hline$[\mathrm{t}]$ & -0.23 & 0.23 & -0.25 & 0.90 & -0.76 & 0.31 & 2.37 & 1.33 & 1.51 & 1.13 & -1.91 & 3.54 & 2.16 \\
\hline \multicolumn{14}{|c|}{ Market value-weighted } \\
\hline$r^{e}$ & 9.63 & 8.29 & 6.01 & 6.78 & 5.05 & 4.58 & 8.92 & 8.85 & 7.03 & 9.14 & 3.04 & 5.89 & 1.31 \\
\hline$[\mathrm{t}]$ & 2.15 & 2.18 & 1.85 & 1.98 & 1.31 & 1.45 & 2.42 & 2.82 & 2.07 & 2.23 & 0.67 & 1.93 & 0.33 \\
\hline SR & 0.62 & 0.63 & 0.53 & 0.57 & 0.38 & 0.42 & 0.70 & 0.81 & 0.60 & 0.64 & 0.19 & 0.56 & 0.10 \\
\hline$a$ & 2.50 & 2.31 & 0.89 & 1.31 & -1.30 & 3.80 & 2.23 & 3.21 & 0.67 & 1.41 & -5.34 & 7.56 & 3.76 \\
\hline$[\mathrm{t}]$ & 0.87 & 0.92 & 0.42 & 0.59 & -0.56 & 1.19 & 1.29 & 2.07 & 0.49 & 0.90 & -2.62 & 2.51 & 1.00 \\
\hline
\end{tabular}

